\title{
Balancing body perception during growth and development
}

\author{
Jolanda S. van Vliet
}

I.UU UNKKDENG

Division of Paediatrics

Department of Clinical and Experimental Medicine

Faculty of Medicine and Health Sciences

Linköping University, Sweden 
(C) Jolanda S. van Vliet

Published articles (Papers I, II, III) have been reprinted with permission of the copyright holders according to the copyright licences for respective journal

Printed by LiU-Tryck, Linköping, Sweden, 2015

ISBN 978-91-7685-947-6

ISSN 0345-0082 
To all of you who walked parts of the road with me

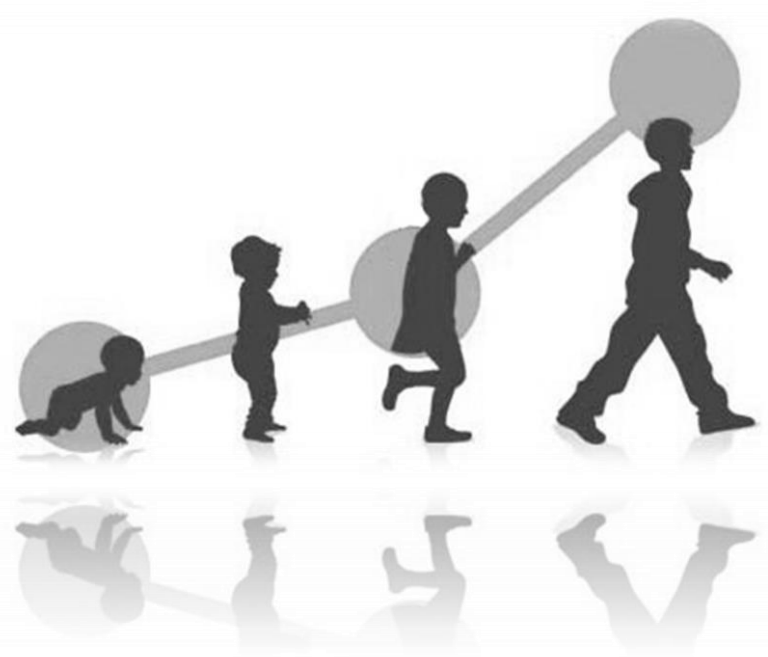

"It takes courage to grow up and become who you really are" E.E. Cummings 


\section{Contents}

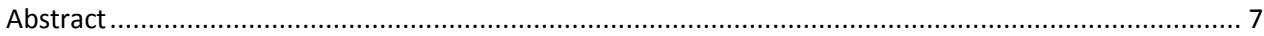

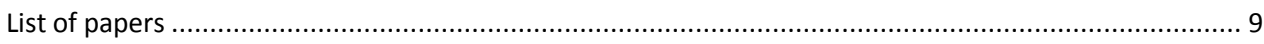

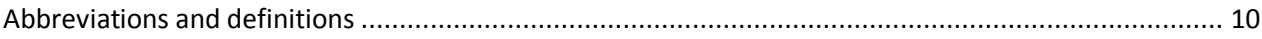

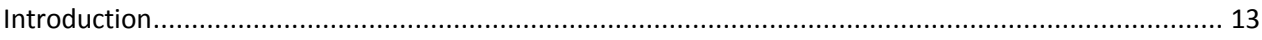

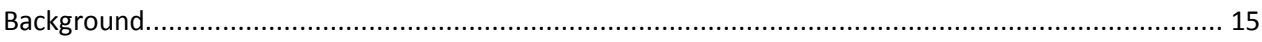

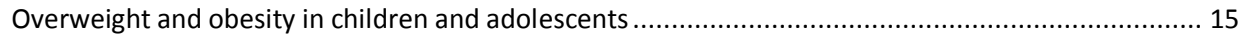

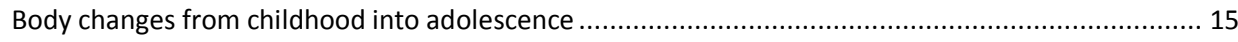

Body image, body perception and body satisfaction .................................................................. 17

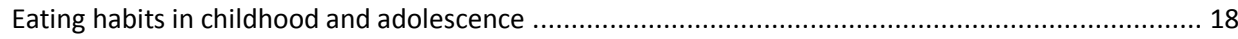

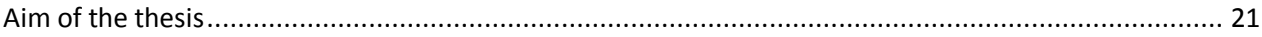

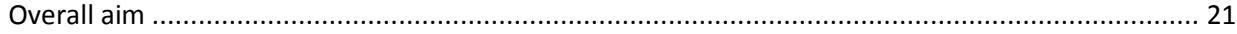

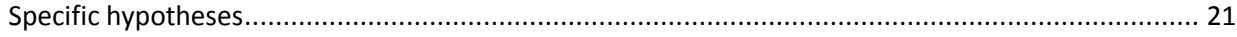

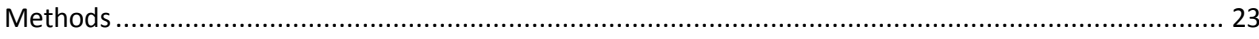

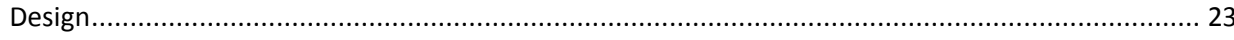

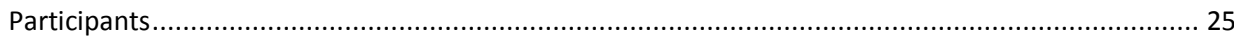

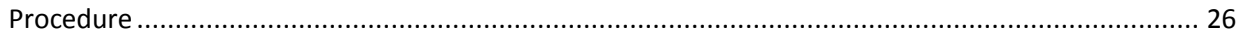

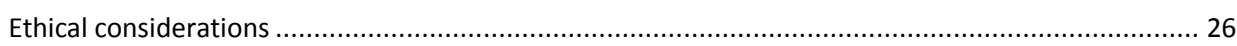

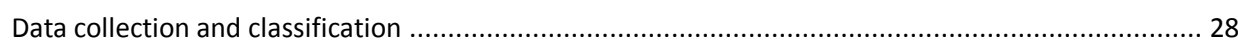

Physical measurements and classification of overweight and obesity ......................................... 28

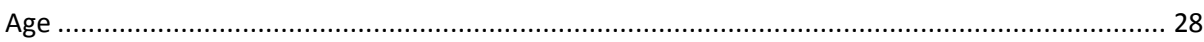

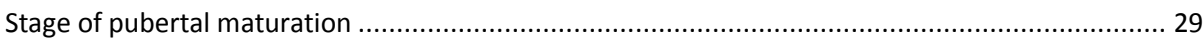

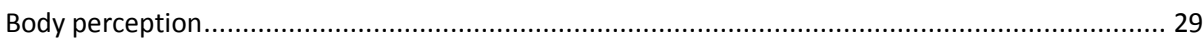

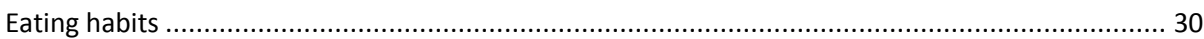

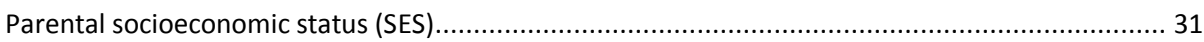

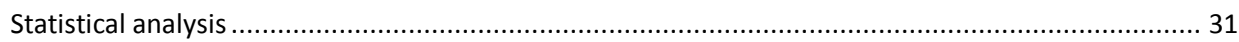

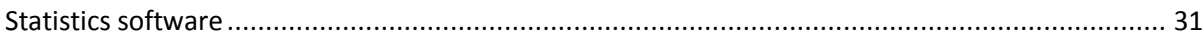

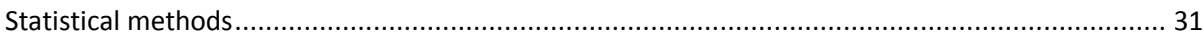

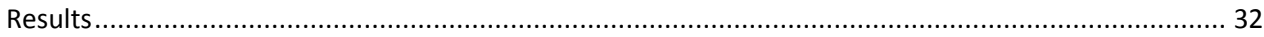

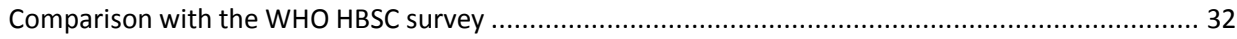

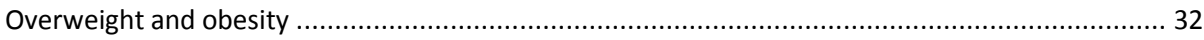




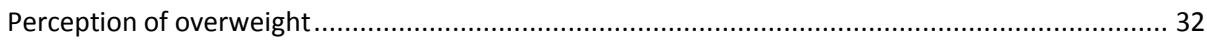

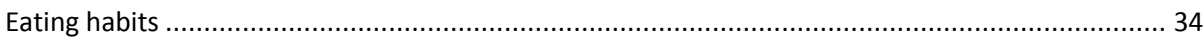

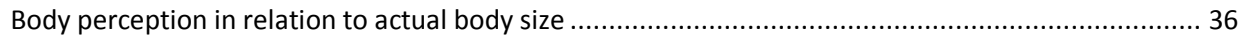

Body perception in relation to female pubertal development .............................................................. 37

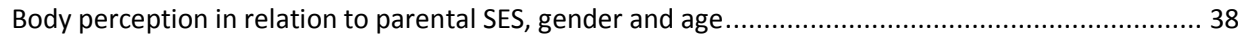

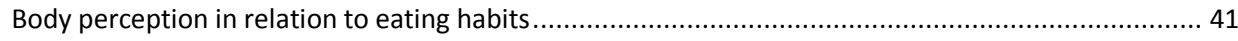

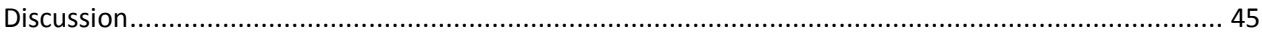

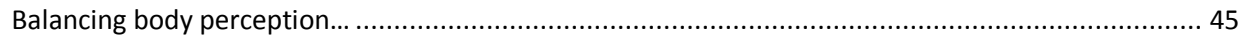

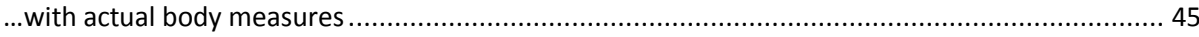

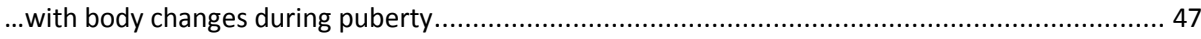

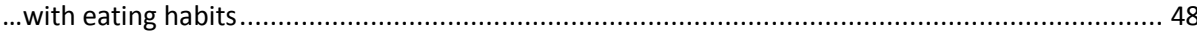

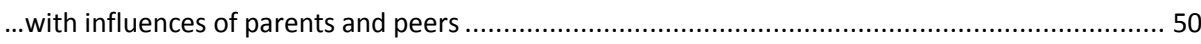

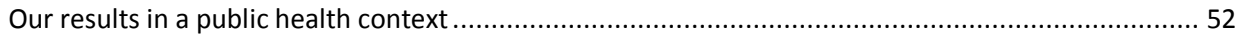

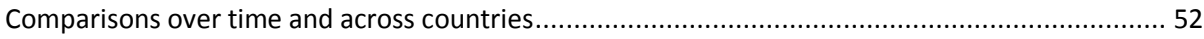

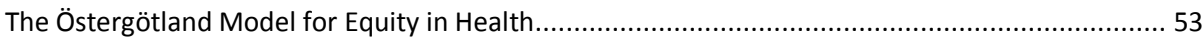

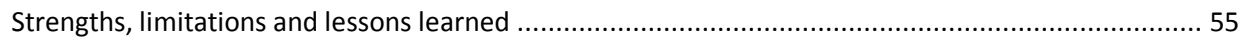

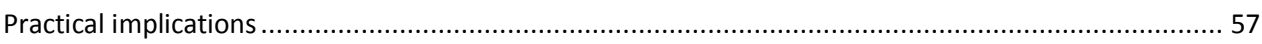

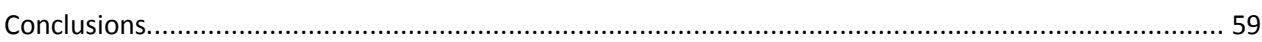

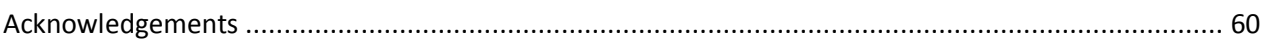

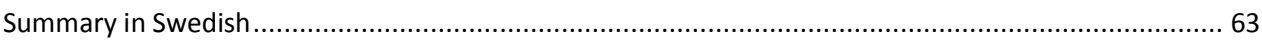

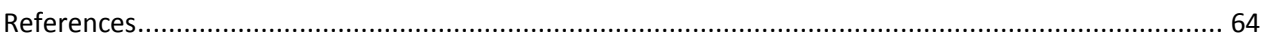




\section{Abstract}

Among children and adolescents, the drive to be slender and the fear of being fat is a growing public health concern. This trend stands in contrast to the increasing prevalence of overweight reported worldwide. Both feeling too fat and being overweight are associated with physical, psychological and social health-related issues from a short- and long-term perspective. The aim of this thesis is to study body perception in relation to actual body size and the bodily changes that occur naturally during puberty. Another objective is to identify risk factors for overweight, overweight perception and unhealthy eating habits in childhood and adolescence.

This thesis describes the prevalence of 1) perception of overweight, 2) overweight/obesity and 3) unhealthy eating habits in Finland and Sweden. We compare our results with the World Health Organization (WHO) Health Behaviour in Schoolchildren (HBSC) survey in 2001/2002 and 2009/2010. Our cross-sectional studies were performed on a female cohort of 11-18 year old girls in Finland and a cohort of boys and girls 7-17 years in Sweden.

In both Finland and Sweden, the prevalence of overweight increased over time, especially among boys. Also perception of overweight increased over time - not just among girls, but also among boys. We found social inequality in overweight, particularly in boys in relation to maternal socioeconomic status. No social inequality, but age and gender differences were found in relation to perception of overweight, where girls older than 13 years showed the highest prevalence. Body perception among girls agreed better with international reference values for waist circumference (WC) than for body mass index (BMI). Breast development and acne increased the risk for overweight perception, particularly among non-overweight girls. Perception of overweight was the strongest risk factor for dieting and skipping breakfast in both boys and girls. These behaviours were more common among adolescents than among younger boys and girls. Skipping breakfast was related to unbalanced food consumption patterns in both sexes, but in a gender-specific way.

We have shown that body perception during growth and development relates to a complex age- and gender-specific balance between body size, stage and timing of pubertal maturation, eating habits as well as parental and peer influences. From a broader perspective, improving adequate body perception entails optimising this balance by influencing one or more of the individual, societal and environmental factors that determine health outcomes among children and adolescents, tracking into adulthood. 


\section{List of papers}

This thesis is based on the following papers:

I. van Vliet JS, Kjölhede EA, Duchen K, Räsänen L, Nelson N. Waist circumference in relation to body perception reported by Finnish adolescent girls and their mothers. Acta Paediatr 2009;98:501-506

II. van Vliet JS, Räsänen L, Gustafsson PA, Nelson N. Overweight perception among adolescent girls in relation to appearance of female characteristics. Paediatrics and Health $2014 ; 2$

III. van Vliet JS, Gustafsson PA, Duchen K, Nelson N. Social inequality and age-specific gender differences in overweight and perception of overweight among Swedish children and adolescents: a cross-sectional study. BMC Public Health 2015;15

IV. van Vliet, JS, Gustafsson PA, Nelson N. Feeling "too fat" rather than being "too fat" increases unhealthy eating habits among adolescents - also in boys. Submitted to Food \& Nutrition Research, August 2015 


\section{Abbreviations and definitions}

$B M I=$ Body Mass Index

$C I=$ Confidence Interval

FORSS $=$ Medical Research Council of Southeast Sweden

$H B S C=$ Health Behaviour in School-aged Children

$H U B R O=$ Helseunders $\varnothing$ kelsen i Oslo - The Oslo Health Study

$I s o B M I=$ age and gender-specific BMI for children up to 18 years

IsoBMI 25 = age and gender-specific BMI for overweight

IsoBMI $30=$ age and gender-specific BMI for obesity

$O R=$ Odds Ratio

$S D=$ Standard deviation

$S E S=$ Socioeconomic status

$W C=$ Waist circumference

$W H O=$ World Health Organization

$W H R=$ Waist-hip-ratio

\section{Brief descriptions and definitions of terms used}

Body image

The individual's perception of the physical appearance of the body; a construct referring to an estimation of body size together with a subjective evaluation of the mental image Body perception

The individual's assessment of the physical aspects of the body and the extent to which this assessment is accurate

Body satisfaction

The extent to which an individual is content with body size and shape Eating habits

The ways in which individuals select, combine and consume meals and foods Food consumption

The frequency of consumption of breakfast, lunch, dinner, snacks, fruits, vegetables, sweets and sugary drinks on schooldays 
Overweight/Obesity according to BMI

Age and gender-specific IsoBMI 25 for overweight and IsoBMI 30 for obesity

Overweight/Obesity according to $W C$

Age and gender-specific cut-off points for overweight and obesity based on WC using the

$90^{\text {th }}$ and $95^{\text {th }}$ percentiles in British children for overweight and obesity respectively

Perception of overweight

Subjective interpretation of the physical appearance of the body as "too fat" or "far too fat"

Self-rated stage of pubertal maturation

How the individual perceives and evaluates the developmental stage of each female

pubertal characteristic: breast growth, acne, pubic hair growth, growth spurt and menarche using a self-administered rating scale for puberty

Skipping meals

Consumption of breakfast, lunch or dinner, respectively, on school days fewer than five times a week

Weight control or dieting behaviour

The practice of regulating food consumption intentionally to control or reduce body weight 


\section{Introduction}

There is a dichotomy of concerns surrounding body image, weight control and body weight in children and adolescents. Weight control measures practiced by people who feel dissatisfied with their body are associated with negative physical and psychological short- and long-term consequences (1). Meanwhile, the prevalence of overweight and obesity is rising, which is also associated with immediate and long-term consequences for physical and psychological health $(2$, 3). The transition period from childhood to adolescence is characterized by rapid physical, psychological, social and behavioural changes (4). During this period, balance between body perception and actual body measures is particularly important to ensure that young people maintain a healthy body weight and are protected from both the pressures related to a negative body image and inappropriate weight control practices.

From a public health perspective and regardless of other known risk factors for development of overweight and obesity, it is important to understand body and weight perception among children and adolescents in relation to actual body and weight measurements, as well as consequent behaviours (5), so as to avoid both further weight gain in cases of underestimation and to prevent unhealthy weight control behaviours in cases of overestimation of the body (5). 


\section{Background}

\section{Overweight and obesity in children and adolescents}

A major public health concern worldwide, including in Scandinavia, is the increasing prevalence of child and adolescent overweight and obesity, especially in groups with low socioeconomic status (SES) $(2,6,7)$. This growing social inequality in overweight and obesity matches the pattern also seen in adults. The higher overweight prevalence among children and adolescents of low SES may relate to a more obesogenic environment with limited access to healthy foods and fewer opportunities to engage in physical activity $(8,9)$.

The prevalence of overweight and obesity is not related to age, but gender differences are apparent. Boys tend to be more overweight than girls (10). Possible reasons may include a stronger focus on weight control and healthy foods during puberty among girls, higher consumption of fast food by boys and less encouragement by parents for boys to control their weight $(2,10)$.

The most important long-term consequence of childhood and adolescent obesity is persistence into adulthood (11-13). Early overweight and obesity have been shown to be significantly associated with long-term morbidity and mortality (4). Further, negative stereotypical attitudes towards obesity may generate discrimination in the school and work settings later in life $(14,15)$. Overweight is also found to be one of the strongest predictors for body dissatisfaction (16).

\section{Body changes from childhood into adolescence}

Body mass index (BMI) is used worldwide as a measure to quantify the appropriateness of body weight. The BMI cut-off points for overweight and obesity are internationally agreed upon (17). In children and adolescents, BMI increases with chronological age and varies according to gender and with stage of puberty. The international reference values for BMI are therefore adjusted by age and gender (17). Healthcare professionals and researchers can use these reference data at the population level. At the individual level, however, the value of BMI is difficult to interpret since BMI is an indirect measure of weight and height and highly dependent on body composition (18, 19). When interpreting BMI, both fat and lean components of body mass must be taken into 
consideration since lean components contribute relatively more to total body weight than fat components (20).

Several studies in both adults and adolescents show that body composition is a better predictor of obesity-related metabolic complications than body weight (21-24). Waist circumference (WC) is a highly sensitive and specific measure of abdominal body fat in both young people and adults (25-27). Body fat distribution, especially abdominal obesity, has become a matter of concern since it is an important risk factor for many diseases. In adults, health professionals use WC as a screening tool for weight-related health problems (28). Among children and adolescents, WC is gender-specific and increases with age (29). WC also reflects the fat patterning that occurs during pubertal maturation.

During puberty, apparent sexual dimorphism in fat patterning occurs in which adolescent girls, as compared with prepubertal children and boys, show a relative decrease in the amount of waist fat and a simultaneous increase in hip fat (30). This means that during pubertal development girls attain a lower waist-hip ratio (WHR) with an apparent "pear" shape, while prepubertal children and boys, who have, or maintain, a higher WHR, display an "apple" shape. Boys gain larger amounts of fat-free muscle mass and skeletal mass, whereas girls acquire significantly more fat mass (30-32). The rapid increase in body fat during pubertal development among girls usually appears following significant changes in body hair and breast development. Menarche occurs relatively late in female maturation, after breast growth and change of fat patterning have already begun and growth velocity has peaked $(33,34)$.

The relationship between total body fat, body fat distribution and onset of pubertal maturation is controversial (35-37). High body fat is believed to promote earlier maturation (3840). However, Buyken et al. suggested that prepubertal body composition may not be critical for initiation of the pubertal growth spurt, but that it affects progression of pubertal development and leads to earlier attainment of later pubertal stages (41). At the same time, they concluded that large WC at the prepubertal stage combined with early menarche increases the risk of overweight in late adolescence among girls (41). Other studies also show that girls who mature early or more rapidly tend to have more subcutaneous truncal fat than same-aged peers $(42,43)$. In boys, however, earlier maturation is associated with lower adiposity and weight (44).

During puberty, the underlying biological processes resulting in the physical changes described here have psychological, social and behavioural implications with probable health- 
related consequences $(45,46)$. Individual capacity to adapt to the changes occurring in puberty is important and depends at least in part on the timing of puberty in relation to the majority of their same-aged peers (46). The onset of puberty varies between individuals, as does the pace of physical changes in both boys and girls (32). In general, synchrony with the majority of peers facilitates adjustment to bodily changes (46). Early maturation entails relatively more rapid changes and is therefore potentially more stressful to the individual. In girls, early maturation has been found to be associated with increased risk for overweight and more unbalanced eating behaviour (47-49). Furthermore, early maturation is associated with a wide range of factors, including genetic, biological, stress, socioeconomic status, nutrition, exercise, and as described above, body fat and body weight $(40,42)$. During puberty, young people become increasingly body-conscious; out-of-sync maturation compared with peers may affect how they feel about themselves and relate to others $(32,50)$. Consequently, out-of-sync maturation may negatively impact social and health-related behaviour, especially among young girls $(46,47)$.

\section{Body image, body perception and body satisfaction}

The naturally occurring physical changes during female pubertal development may contribute to negative body image, since the often rapid increase in body fat among girls is considered to be a negative attribute in Western Europe $(51,52)$. Boys going through puberty, however, become more muscular and develop broader shoulders, which correlates positively with notions of an ideal male body shape $(53,54)$.

The literature uses several terms to describe how the physical appearance of the body is perceived. Body image is perhaps most common. Body image is a construct referring to an estimation of body size together with a subjective evaluation of the mental image. Body image as a psychological construct is part of self-image and self-esteem (1). According to a recent British evidence assessment, body image as used in the literature can refer to either body perception or body satisfaction (55). Body perception is defined as an individual's assessment of the physical aspects of his or her body and the extent to which this assessment is accurate. In extreme cases individuals suffer from body dysmorphic disorder (BDD), a psychological condition related to eating disorders in which individuals have highly distorted perceptions of their body size. Body satisfaction is the extent to which individuals are content with their body size and shape. Incorporated into the concept of body satisfaction are terms such as body confidence, body esteem, and body dissatisfaction (55). This thesis mainly uses the term body perception, 
especially regarding our own results, since it most closely reflects the parameters we studied. However, we also use the other terms when appropriate in relation to the research described and discussed.

The concept of body perception is cultural, complex and multidimensional (56). Gender differences are apparent in the ways in which male and female adolescents evaluate their bodies; girls tend to view their bodies primarily as a means of attracting others, while boys perceive their bodies as a means of effectively operating in the external environment (54). Individuals often find it difficult to make appropriate judgements and draw the right conclusions about their own weight and body size, particularly during puberty when rapid changes are not always synchronized with the developmental pace of peers (50). Girls in particular often feel fat and are dissatisfied with their bodies as a consequence of an increase in body fat during pubertal maturation and cultural influences pertaining to slimness and dieting (57). For many girls, the goal may therefore be not normal weight, but underweight, while boys are more likely to perceive themselves as underweight and therefore engage in weight-gaining activities such as muscle enhancement (54, $58,59)$. Thus, body perception rather than actual body weight has emerged as a potent driving force behind unhealthy weight control behaviours, especially among girls, with higher parental education being linked to higher demands concerning appearance and weight (60).

Meanwhile, overweight among both boys and girls is also a strong predictor for body dissatisfaction. Since higher overweight prevalence is associated with lower SES, social differences in body perception may stem partly from overweight as one of the strongest predictors for body dissatisfaction (16). Also, children from lower SES households are found to underestimate overweight compared with their respective counterparts, and may therefore lack motivation to avoid further weight gain since their opportunities to change their eating habits are limited by their SES (5).

\section{Eating habits in childhood and adolescence}

Balanced and appropriate eating habits during childhood and adolescence, such as regular meals and healthy food choices, are likely to reduce both short and long-term risks of health-related problems. Such health problems may manifest as dental caries and constitutional growth delay, as well as overweight and obesity (61). Eating habits change during adolescence to reflect the weakening influence of parents and the growing influence of peers $(62,63)$. During childhood, parents influence food consumption by limiting availability and accessibility, as well as through 
modelling, positive reinforcement and discipline $(64,65)$. It is well known that girls mature earlier than boys, suggesting that parents have less influence on girls than on boys of similar age. Lower SES is associated with an increased prevalence of overweight and obesity among adults in developed countries. This fact suggests that parents with low SES are at greater risk of being overweight themselves due to the social norms and behaviours of their social class (66). In addition to hereditary factors, children of low SES, boys in particular, may therefore be at increased risk of overweight and obesity by adopting the norms and eating habits of their parents, who serve as role models (67). In adolescence, however, the need to express freedom from parental control and the forging of identity can manifest through increased consumption of meals outside the home or school, often comprising fast foods (68). The newly assumed patterns of meals and snacking may compromise dietary content during adolescence since such changes reduce consumption of fruits and vegetables while increasing intake of soft drinks and sweets (69).

Regular meals, especially breakfast, are associated with a better diet that includes fruits and vegetables and lower consumption of soft drinks (2). BMI and overweight prevalence are generally lower among children and adolescents who eat breakfast (70). Conversely, studies indicate that those who are overweight are more likely to skip breakfast, be less physically active and watch television more often (2). Moreover, consumption of sugar-sweetened beverages, including soft drinks, has risen worldwide and has been accompanied by the described increase in the prevalence of overweight and obesity (69). Lower family SES tends to be associated with higher soft drink consumption and less frequent daily breakfast consumption (65).

Both breakfast and soft drink consumption are higher among boys. Boys have higher calorie requirements, which may steer them towards more energy-dense foods (71). The increased prevalence of soft drink consumption as children age may result from the greater opportunities teenagers have to select and purchase their own food and beverages outside the home. Gender differences in eating habits may be attributable to the greater focus girls place on weight control $(68,72)$.

The desire to be thin and the stigma of obesity may be of particular concern to girls and may have a significant effect on body image, self-esteem and weight control behaviours $(72,73)$. Healthy pursuit of weight management is an important element to maintain health. Weight control behaviours resulting from body dissatisfaction, however, include unhealthy practices such 
as skipping breakfast and an overemphasis on calorie reduction (74-76). Such practices may be associated with negative physical and psychological effects such as irritability, concentration problems, menstrual irregularities, nutritional deficiencies and eating disorders (77).

Paradoxically, repeated weight control behaviour to reduce weight may lead to weight gain due to a pattern of long-term binge eating and fasting, followed by periods of overeating or through the consequences of decreased breakfast consumption (78).

Unhealthy food consumption patterns and dieting behaviours in children and adolescents have become a major public health concern. In western societies, daily consumption of breakfast, fruits and vegetables is considered to be an indicator of healthy eating habits. However, studies have shown that skipping breakfast, along with low consumption of fruits and vegetables combined with high consumption of soft drinks and sweets are common among adolescents (68, 79). The eating habits of children and adolescents are of special concern since behaviours formed early in life are likely to persist into adulthood (80). 


\section{Aim of the thesis}

\section{Overall aim}

The overall aim of this thesis is to study body perception in relation to actual body size and the bodily changes that naturally occur during growth and development in the transition from childhood into adolescence. Attention was paid to identify risk factors that could prompt unhealthy eating habits, food consumption behaviours and weight-related health problems later in life.

\section{Specific hypotheses}

Body perception was examined in all four sub-studies. The first two sub-studies examined its association with measures of actual body size and characteristics of female development (I, II). The two other sub-studies examined the impact of gender, age and parental socioeconomic status on body perception and body size, as well as how they relate to eating habits (III, IV).

The four papers explore the following hypotheses:

I. Waist circumference is easier to interpret than BMI and therefore more closely related to body perception in adolescent girls

II. Early appearance of female characteristics is related to overweight perception

III. Gender differences in body perception are related to the differentiation in body composition that naturally occurs with age during adolescence; body weight and composition are associated with parental socioeconomic status

IV. Eating habits in girls are related to attempts at weight control, especially among those who perceive themselves as overweight, whereas little is known about the association between eating habits among boys with body perception and overweight/obesity. 


\section{Methods}

\section{Design}

This thesis contains a descriptive time-lag study involving two countries comparing the results from our cross-sectional studies 1 and 2 with the results of the international World Health Organization (WHO) Health Behaviour in School-aged Children (HBSC) survey, regarding BMI, body perception and eating habits (see figure 1) $(81,82)$.

Study 1 is a cross-sectional study of data collected between 1997 and 2000 concerning the accuracy of body perception in relation to measurements of body size and self-reported characteristics of female pubertal development. Papers I and II present the results of study 1, as shown in table 1.

Study 2 is a cross-sectional study conducted in 2010 on socioeconomic, gender and age differences in relation to measured overweight and perception of overweight, as well as associations with eating habits. Papers III and IV present the results of the measurements taken in 2010 (table 1).

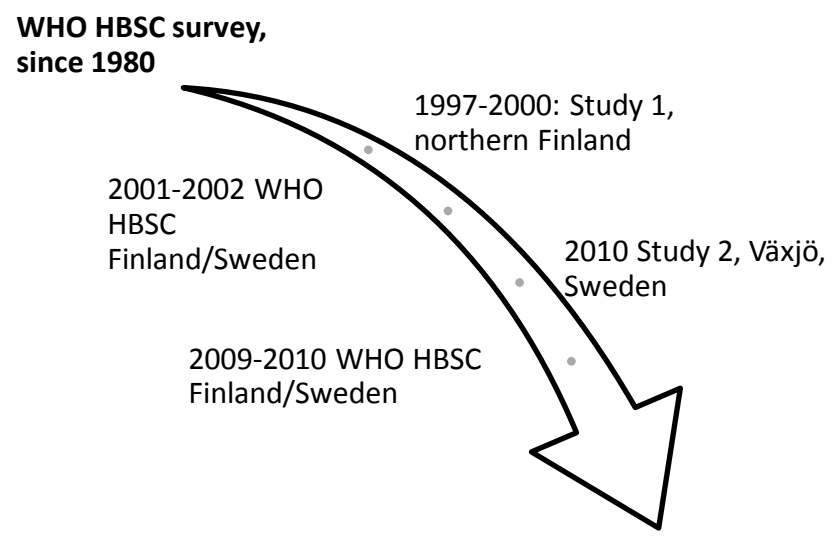

Figure 1. Descriptive study design based on the results of cross-sectional study 1 in northern Finland 1997-2000, cross-sectional study 2 in Växjö, Sweden, 2010, compared with the WHO HBSC survey in Finland and Sweden 2001-02 (81), and 2009-10 (82) 


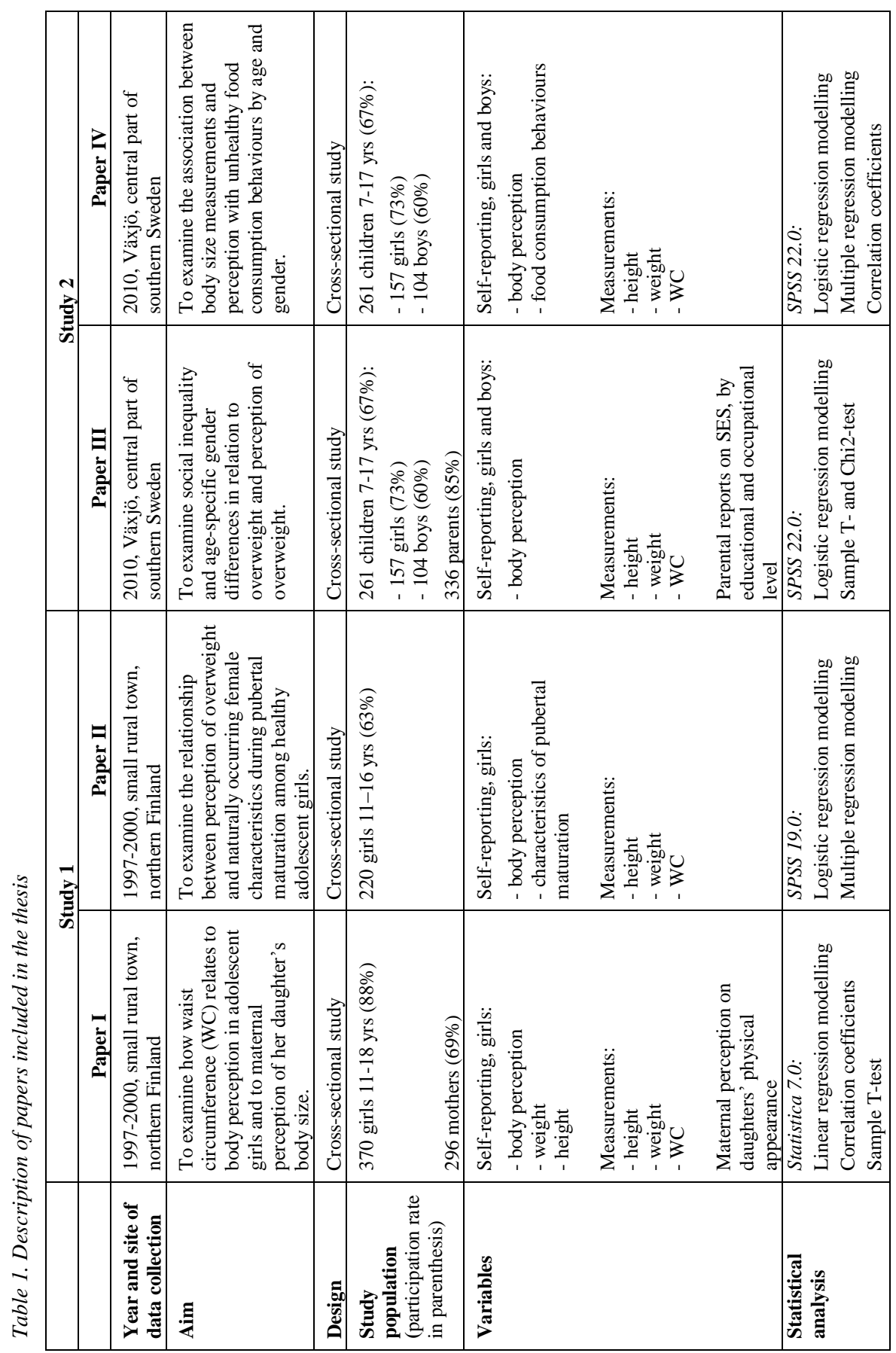




\section{Participants}

\section{Paper I and II:}

The study population in our cross-sectional study 1 consisted of all girls in grades 5 through 12 , attending any school in a small rural town in arctic Finland, as well as their parents. Once a year for three consecutive years all girls in grades 5 through 12 were invited to participate by completing a questionnaire followed by anthropometric measurements obtained during a visit by the research team to the schools. Only girls were included because this study was part of a larger study concerning body perception and dietary behaviour in girls. Families received an invitation letter containing a questionnaire to be completed by one parent at home.

Pooled data on 296 parents (69\% participation rate) and 370 girls (88\% participation rate) who participated in at least one of the three measurement periods were analysed. Among girls and parents who participated in the study more than once, only data from the first measurement were included in the pooled dataset. To study possible bias in the pooled data due to awareness of the study during the second and third years, pooled data were compared with data from the first year $(n=213)$. To evaluate the characteristics of the dropouts, we compared data from girls participating only once $(n=199)$ with those of girls participating all three years $(n=72)$. In addition, we compared data from the group completing both the body measurements and the questionnaire $(\mathrm{n}=286)$ with those who did not participate in body measurements $(\mathrm{n}=50)$. Analyses of data from dropouts showed no significant differences in anthropometric measurements between girls who participated once $(n=199)$ compared with girls who participated all three times $(n=72)$.

Among adults answering the questionnaire, $95 \%$ were mothers $(n=281), 5 \%$ fathers $(n=$ 14) and $0.3 \%$ stepmothers $(n=1)$. Unfortunately, the number of participating fathers was too small for separate analyses of their responses, or for including them in the group as a whole, since we cannot assume that paternal and maternal answers are equivalent. Therefore fathers were excluded from further analyses.

\section{Paper II:}

The study population was the same as described in paper I above. Paper II included only the 220 girls aged 11-16 years who participated in both the questionnaire and the anthropometric measurements $(63 \%)$. 


\section{Papers III and IV:}

In cross-sectional study 2, children and adolescents aged 7 to 17 attending grades two through six in a primary school and grades seven through nine in a secondary school in Växjö, Sweden, were invited to participate in the study consisting of a written questionnaire and anthropometric measurements $\left(\mathrm{N}_{\text {total }}=391\right)$. Their parents were invited by letter to provide additional information in a written questionnaire in which background variables on SES were the most relevant for the study in question. Sixty seven percent $(n=263)$ of all children and adolescents participated in this study during the autumn of 2010. Participation rates among boys and girls were $60 \%\left(\mathrm{~N}_{\text {total boys }}=175\right)$ and $73 \%\left(\mathrm{~N}_{\text {total girls }}=216\right)$, respectively. Among parents, $85 \%\left(\mathrm{~N}_{\text {total }}\right.$ parents $=395$ ) returned the questionnaire.

\section{Procedure}

Both oral and written presentations of the study were delivered to the children and adolescents in their classrooms during school hours, and to their parents at special evening events at the schools, some weeks prior to study start and requesting consent. Information was provided on participant confidentiality, which was ensured by taking measurements in private and by encoding each participant immediately after consent. The participating girls (in Finland and Sweden) and boys (only in Sweden) completed the questionnaire in the classroom where either the researchers (in Finland) or school personnel (in Sweden) were present to ensure that individuals completed the questionnaires on their own and in privacy. After that, the anthropometric measurements were individually obtained in private by the researchers (in Finland) or the school nurse (in Sweden) using calibrated school equipment. All measurements were taken at school during school hours.

\section{Ethical considerations}

Research involving young people requires careful ethical scrutiny. Ethical practice goes beyond the formal ethical requirements and procedures such as approval from the ethical board, the involved schools and a statement signed by participants or their parents, as described below. Every person, regardless of age, has the right to privacy and to be treated with dignity. No person should be asked to cooperate in a study that may result in a sense of self-denigration, 
embarrassment or cause personal harm in the short- or long-term. Reflection on these aspects prior to study start is particularly relevant in our studies on body perception, body size and behavioural consequences during the sensitive period of growth, development and adolescence. At the same time, important knowledge concerning these issues during growth and development can only be obtained through the contributions and participation of children and adolescents. Ethical practice entails thorough consideration by researchers concerning the health risks and efforts of participants in relation to the benefits gained, such as knowledge and a better understanding of adolescent growth and development, which improve health among children and adolescents both in the short- and long-term. Conducting our studies according to such ethical reflections and considerations means that the researcher serves as a trustee of integrity and truth, and must remain critically aware of ethical conduct throughout.

\section{Paper I and II:}

Written consent was obtained from both parents and participants before taking any measurements. All measurements were taken at school during school hours. Participation was voluntary and participants were not compensated in any way. The local health centre and the involved schools approved and cooperated with the study. The study plan was approved by the committee for research ethics of the Faculty of Agriculture and Forestry, University of Helsinki, Finland. The research was conducted in accordance with prevailing ethical practices at the time of data collection in Finland in compliance with the Helsinki Declaration regarding human subjects.

\section{Papers III and IV:}

The research contained here was part of a larger research project and it preceded by written information in five languages (Swedish, Arabic, Albanian, Somali and Serbo-Croatian) regarding the purpose of the research along with information on voluntary participation, consent and confidentiality for all participants and their families at the school. The families were also invited to informational meetings with the research group. Written parental informed consent was obtained before the study from all parents and from all children from seventh grade (12-13 years old) and up. The study was approved by the Regional Ethical Review Board in Linköping D-nr 07-182. 


\section{Data collection and classification}

\section{Physical measurements and classification of overweight and obesity}

Physical measurements were obtained regarding height, weight, waist and hip circumference. The children were measured wearing light clothing, $\mathrm{t}$-shirt and trousers, but without shoes and belts. Height was measured to the nearest $0.1 \mathrm{~cm}$ and weight to the nearest $0.1 \mathrm{~kg}$. Hip circumference was measured at the widest point to the nearest $0.1 \mathrm{~cm}$. Waist circumference was measured to the nearest $0.1 \mathrm{~cm}$ midway between the tenth rib and the iliac crest.

In addition to the directly obtained physical measurements, we calculated body mass index $\left(\mathrm{BMI}=\right.$ weight $/$ height $\left.^{2}\right)$ and waist-hip ratio (WHR) for each respondent. The weight status of each adolescent was categorised using the age- and gender-specific BMI cut-off points for overweight (IsoBMI 25) and obesity (IsoBMI 30) presented by Cole et al. (17). Cole and coworkers did not present any cut-off points for underweight and severe underweight and since our study focuses on overweight and overweight perception, only the three categories obese, overweight and non-overweight were used. For the age- and gender-specific cut-off points for overweight according to $\mathrm{WC}$, we used the $90^{\text {th }}$ and $95^{\text {th }}$ percentiles for overweight and obesity respectively, developed by McCarthy et al. (83).

\section{Age}

To assess the age of the participants, date of birth was asked for in the written questionnaire as well as at the occasion of the physical measurements.

For the overall comparison with the WHO HBSC survey over time and across countries, children and adolescents participating in our studies (1997-2000 in Finland and 2010 in Sweden) were classified so that the mean age of 13-years matched the cross-country HBSC survey data for each year (see Results, table 2).

In papers III and IV, we classified children participating in 2010 into two age groups with a cut-off point at 13 years, where younger children were defined as ages 7 to 12.99 years and older children as $\geq 13$ years. The age 13 cut-off enabled us to compare children before adolescence (mean age $10.4 \pm 1.5$ years; $n=148$ ) with those in adolescence (mean age $15.0 \pm 0.9$ years; $n=113$ ), while also allowing comparison between children attending primary school and teenagers attending secondary school. 


\section{Stage of pubertal maturation}

To assess emergence of female characteristics we chose to use self-reported age at menarche and a self-administered rating scale for puberty developed by Carskadon and Acebo (84). Parameters concerning physical development in this scale included growth spurt, pubic hair growth, skin changes, breast growth, and menstruation. Response options for the first four items were "not yet started," "barely started," "definitely started," "seems complete," and "I don't know" (missing value). Only two responses were possible regarding menstruation: "yes" or "no" and if "yes," the follow-up question was "age at menarche" (84).

When analysing the self-administered rating scale for puberty we chose to treat the items on pubertal maturation separately, rather than calculating a total score as proposed by Carskadon and Acebo (84), since responses to the different items varied for each individual. The responses "not yet started" and "barely started" were categorised into "not started", while "definitely started" and "seems complete" were categorised into "started". One reason we included "barely started" in the "not started" category was because of the small number of individuals in that category, probably because the youngest girls in this study were 11 years old, when most girls begin to show some signs of development. The pubertal maturation scale was dichotomised to diminish individual variation due to uncertainty among the girls regarding the exact position on the response scale and to enable us to calculate the odds ratios of the different pubertal characteristics for overweight perception.

\section{Body perception}

To assess body perception, we phrased the question according to the HBSC questionnaire, "Do you think your body is...", to make comparison with HBSC results possible (85). Response categories were based on the five-point Likert scale and ranged from "far too thin" to "far too fat". A score of four or higher on the Likert scale in response to the question on body perception (those who reported perceiving their body as "a bit too fat" or "far too fat") was used to define overweight perception. Body perception was dichotomised into non-overweight and overweight perception since the study focused on overweight perception.

We defined misconception 1 as perception of overweight in the absence of measured overweight and misconception 2 as perception of non-overweight despite measured overweight. 


\section{Eating habits}

\section{Weight reduction or dieting behaviour}

According to the formulation of the question in the HBSC-survey, participants were asked whether they were currently "on a diet" with options to respond "No, my weight is fine"; "No, but I should lose some weight"; "No, I need to put on weight"; and "Yes" (85). We defined weight reduction behaviour in our papers as a response of either "Yes" or "No, but I should lose some weight". In the comparisons with the HBSC survey we only included the "Yes" responses.

\section{Meal patterns and food consumption}

Questions on how frequently breakfast, lunch (mid-day meal) and dinner (evening meal) were consumed were used to measure meal patterns and formulated according to the HBSC survey (85). Participants were asked to provide separate responses for weekdays and for weekends. "How often do you usually have breakfast (more than a glass of milk or fruit juice)?" with response options for school days: "I never have breakfast during the week"; "One day"; "Two days"; "Three days"; "Four days"; "Five days". The response options for weekends were similar, but this thesis only addresses data from week days. The same type of question was used for all three meals. We categorised responses as skipping breakfast, lunch and dinner on schooldays when consumption of any of these main meals occurred less than five times a week.

In addition, a question on snacking behaviour was posed separately for weekdays and weekends: "How often do you usually have a snack (drink or eat something small like fruit, a sandwich, cookies, or chocolate)?" This thesis only includes the response options for weekdays: "I rarely or never eat snacks"; "I eat snacks several times a week"; "I usually have a snack once a day"; "I usually have a snack twice a day"; "I usually have a snack three times a day".

The question on food consumption was "How many times a week do you usually eat or drink... fruit/vegetables/candy/sugary soft drinks/alcoholic beverages?" Response options were: "Never"; "Less than once a week"; "Once a week"; "2-4 days a week"; "5-6 times a week"; "Once a day, every day"; "Every day, more than once". 


\section{Parental socioeconomic status (SES)}

Self-reports on background variables such as parental SES, as it pertains to level of paternal and maternal education and occupational status were obtained as part of a written questionnaire filled out by parents at home.

Parental SES is classified according to either level of education or occupational status, as defined by Statistics Sweden (86). Level of education for mothers and fathers, respectively, was divided into two categories: those who pursued studies beyond secondary school at college or university were defined as having a higher level of education, while those who left school after graduating from a secondary school were defined as having a lower level. Regarding occupational status, blue-collar workers were classified as having lower occupational status and white collar workers as having higher occupational status, according to the international classification system used by Statistics Sweden (86).

\section{Statistical analysis}

\section{Statistics software}

The collected data were coded and entered into the statistics program Statistica 7.0 (Paper I), SPSS 19.0 (Paper II), and SPSS 22.0 (Papers III and IV), respectively.

\section{Statistical methods}

To compare groups, the t-test was used for continuous variables and the chi-square test for nonparametric variables. We used univariate logistic regression modelling to study the determinants for overweight and perception of overweight, as well as to assess odds ratios (OR). Logistic regression was also used to answer the question of the extent to which perception of overweight may vary with independent variables such as age, gender and socioeconomic status. Multiple regression modelling was used to adjust for variables such as measured overweight according to IsoBMI and WC, perception of overweight and age.

Due to attrition, the number of subjects in separate analyses varied according to what variables were included. The level of significance for all analyses was set at $\mathrm{p}<0.05$. 


\section{Results}

\section{Comparison with the WHO HBSC survey}

Table 2 shows the number of participants and the mean age of the 13-year old boys and girls in the different study populations used in the comparisons across time and countries $(81,82)$. The HBSC survey did not include data on number of participants or separate ages for boys and girls $(81,82)$. Due to the relatively small populations in our cross-sectional studies, variation in age was greater in our study than in the WHO HBSC survey.

Table 2. Number and mean age in years of the 13-year old children included in the comparisons

\begin{tabular}{|r|r|r|r|r|r|r|}
\hline & $\begin{array}{r}\text { Study 1 } \\
\text { Finland 97-00 }\end{array}$ & $\begin{array}{r}\text { HBSC Finland } \\
\mathbf{2 0 0 1 / 2 0 0 2}\end{array}$ & $\begin{array}{r}\text { HBSC Finland } \\
\mathbf{2 0 0 9 / 2 0 1 0}\end{array}$ & $\begin{array}{r}\text { HBSC Sweden } \\
\mathbf{2 0 0 1 / 2 0 0 2}\end{array}$ & $\begin{array}{r}\text { HBSC Sweden } \\
\mathbf{2 0 0 9 / 2 0 1 0}\end{array}$ & $\begin{array}{r}\text { Study 2 } \\
\text { Sweden 2010 }\end{array}$ \\
\hline $\begin{array}{r}\text { Girls } \\
\text { Boys } \\
\text { Total }\end{array}$ & $13.6 \mathrm{n}=220$ & & & & & $13.6 \mathrm{n}=122$ \\
$13.3 \mathrm{n}=76$ \\
$13.5 \mathrm{n}=198$ \\
\hline
\end{tabular}

\section{Overweight and obesity}

Figure 2 shows the prevalence of overweight and obesity among boys and girls over time and across countries. The HBSC data showed that the prevalence of overweight and obesity was higher among boys than girls in both countries. The prevalence increased over time among both boys and girls in Finland, but only among boys in Sweden. The prevalence was somewhat higher among both boys and girls in Finland compared with boys and girls in Sweden. Regarding our 2010 cross-sectional study in Sweden, the prevalence of overweight/obesity was higher among both boys and girls compared with the results of the 2009/2010 HBSC survey in Finland and Sweden. In our 1997-2000 cross-sectional study in Finland, the prevalence of overweight/obesity among girls was lower compared with the results of the 2001/2002 HBSC study in Finland and Sweden.

\section{Perception of overweight}

Figure 3 shows perception of overweight over time and across countries. The prevalence of "feeling too fat" was higher among girls than among boys in both countries, and over time. Overweight perception increased among girls in Finland and Sweden between 2001/2002 and 2009/2010. In both our cross-sectional studies, the prevalence of overweight perception among girls was lower compared with the HBSC results from each country and year, respectively. 
Figure 2. Prevalence of overweight/obesity among 13-year old children

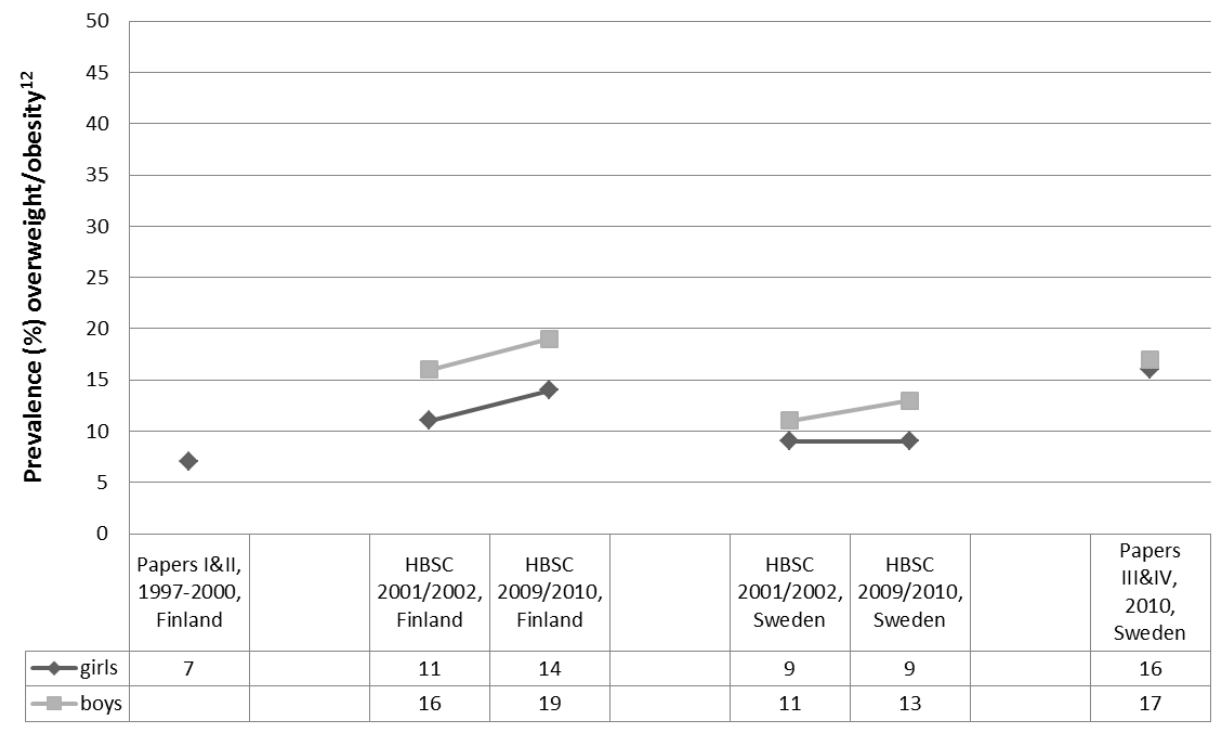

${ }^{1}$ Criteria for overweight, including obesity, according to BMI: IOTF (17). ${ }^{2}$ Prevalence of overweight in our studies is based on data for measured height and weight, while the prevalence of overweight in the HBSC surveys is based on self-reported data for height and weight

Figure 3. Prevalence of perception of overweight among 13-year old children

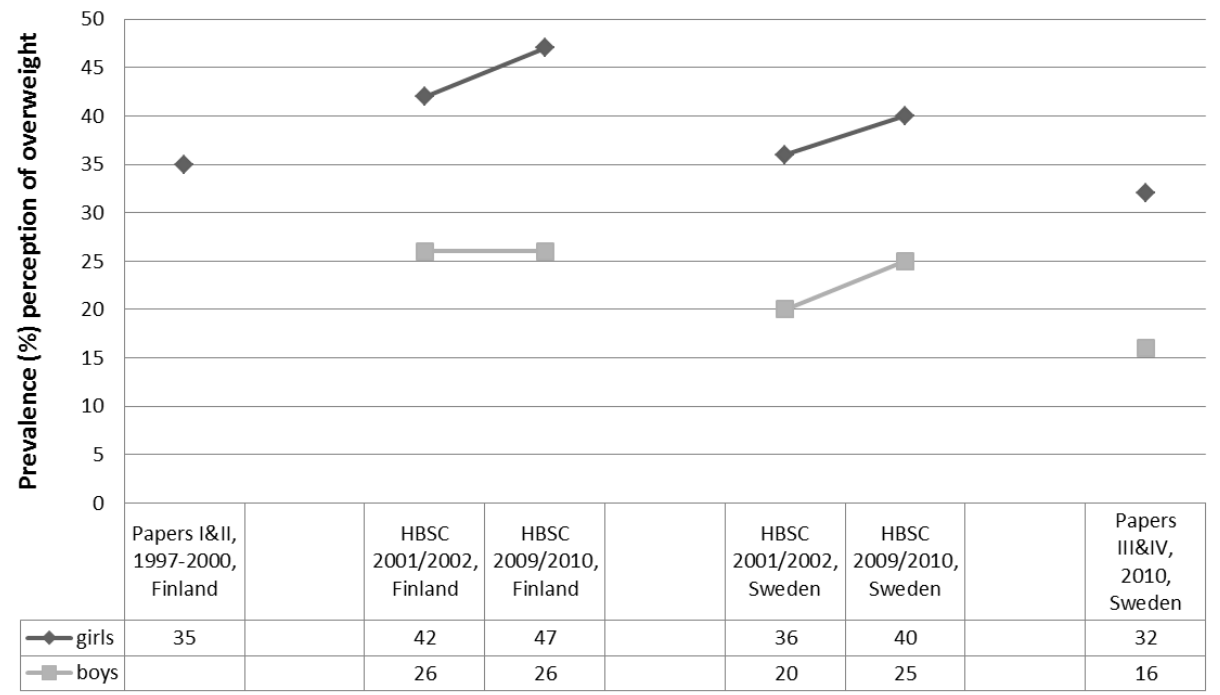


Among boys, an increase in perception of overweight over time was found only in the Swedish results from the HBSC survey. However, among Finnish boys, the prevalence of "feeling too fat" was already higher in 2001/2002 compared with Swedish boys, a finding that persisted in 2009/2010. Just as our Swedish cross-sectional study found among girls, the prevalence of overweight perception among boys was lower than in the 2009/2010 Swedish HBSC study.

\section{Eating habits}

Figure 4 compares weight reduction behaviour from our cross-sectional studies with the results of the 2001/2002 and 2009/2010 WHO HBSC surveys in Finland and Sweden $(81,82)$. Weight reduction behaviour among girls was greater than among boys in both countries. Data from our 1997-2000 cross-sectional study in Finland showed the same amount of weight reduction behaviour as found among girls in the HBSC survey in Finland. There was no change in the prevalence of weight reduction behaviour among girls in Finland between 2001/2002 and 2009/2010. However, a decrease in weight reduction behaviour was found among girls in Sweden over the same time period. The results from our study for Swedish girls show less weight reduction behaviour than the Swedish HBSC results for girls. Our Swedish cross-sectional study also indicated much less weight reduction behaviour among boys than seen in the Swedish HBSC survey concerning boys, both 2001/2002 and 2009/2010. A slight increase in weight reduction behaviour over time was noted among boys in both Finland and Sweden.

Regarding "skipping breakfast", both girls and boys in our cross-sectional studies reported doing so less frequently than indicated by the results of the WHO HBSC study in both Finland 2001/2002 and Sweden 2009/2010. The prevalence of skipping breakfast was higher in Finland than in Sweden. Skipping breakfast was more common among girls than among boys in both countries. In both Finland and Sweden, however, a clear decrease in skipping breakfast was seen among girls from 2001/2002 to 2009/2010. Over the same time period, skipping breakfast increased among boys in Finland, while no such tendency was seen in the Swedish results from the WHO HBSC survey. 
Figure 4. Prevalence of weight reduction behaviour among 13-year old children

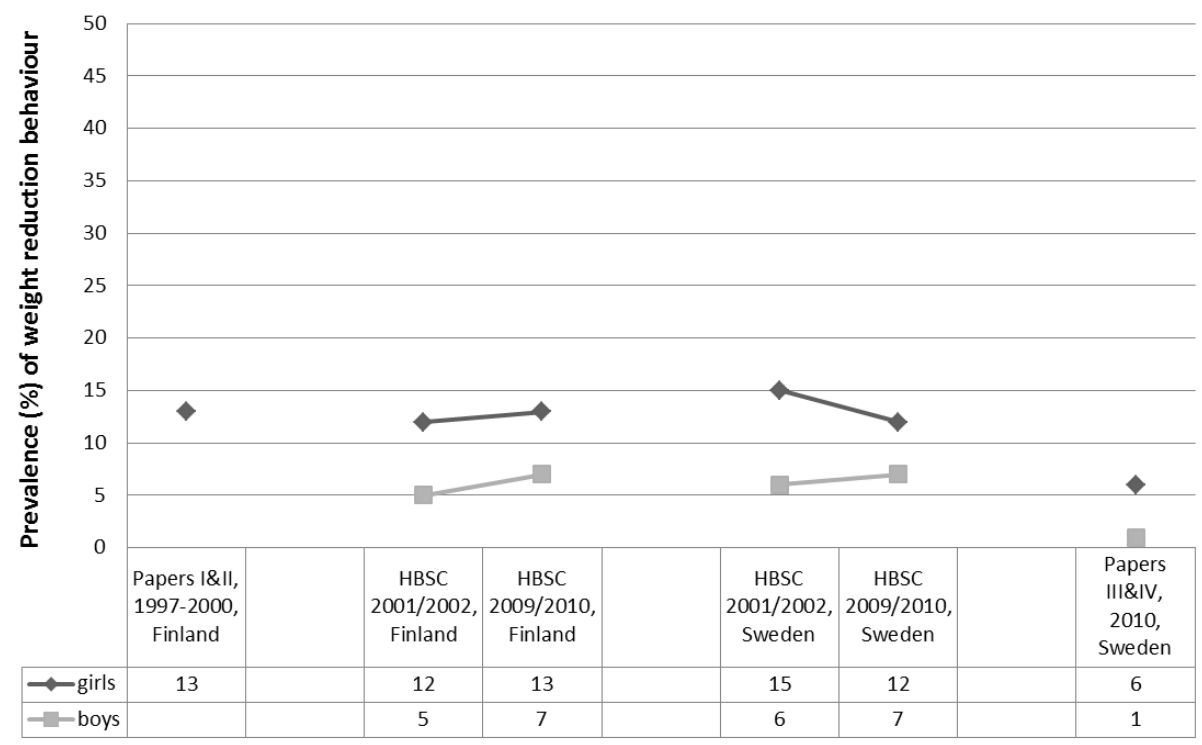

Figure 5. Prevalence of skipping breakfast among 13-year old children

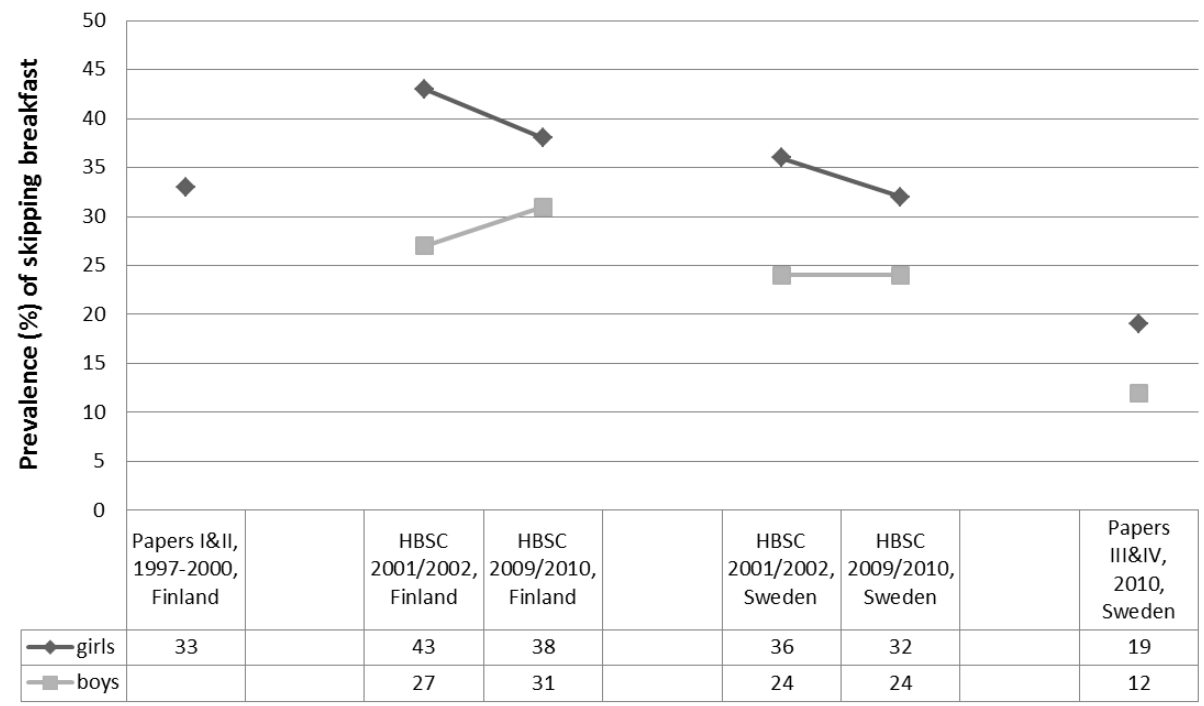




\section{Body perception in relation to actual body size}

We found no significant differences between the measured height of Finnish girls and their selfreported height in centimetres. However, regression modelling on measured and self-reported weight in kilograms showed a slight but significant overestimation at lower weights and underestimation at higher weights $(\mathrm{p}<0.05)$. Underweight individuals overestimated their weight by $0.43 \mathrm{~kg}(\mathrm{n}=29)$, normal weight individuals underestimated their weight by $0.41 \mathrm{~kg}(\mathrm{n}=247)$ and overweight individuals underestimated their weight by $0.84 \mathrm{~kg}(\mathrm{n}=14)$. The mean deviation of self-reported weight from measured weight was $0.34 \mathrm{~kg}(\mathrm{n}=290)$.

Meanwhile, the same cohort of Finnish girls perceived themselves significantly as being fatter than the classification based on their measured BMI ( $p<0.0001)$, but not based on measured WC according to McCarthy's British reference values. When compared with the reference values for BMI and WC, 37\% and 20\% of the Finnish girls $(n=294$ and $n=271)$, respectively, believed themselves to be fatter than indicated by these measurements. In our Swedish study, we found that of the 76 Swedish girls (35\%) perceiving themselves as overweight, only 14 were overweight according to their BMI and 36 according to WC. At the same time, girls with overweight perception $(n=76)$ had in fact significantly higher weight, BMI, WC, hip circumference and WHR than girls without overweight perception $(n=144)(p<0.05)$.

In our Finnish study, the perception of body size of daughters by mothers did not differ from the classification arrived at the international reference values for BMI as defined by the WHO. Mothers classified their daughters as smaller than the classification according to the international reference values for WC $(\mathrm{p}<0.0001)$. When comparing agreement of body perception as judged by the girls and by their mothers, maternal perceptions agreed more often than those of their daughters with the international WHO reference values for BMI $(p<0.001)$. The level of agreement for body perception was similar between the girls and their mothers for classification according to WC.

Analyses conducted on dropouts showed that girls participating only once in the study were more likely to perceive themselves as overweight or obese than girls who participated in all three years of the study $(\mathrm{p}<0.05)$. 


\section{Body perception in relation to female pubertal development}

Girls reporting breast development $(n=144)$ and acne $(n=117)$ were more likely to perceive themselves as overweight than girls who did not ( $n=76$ and $n=86$ for breast growth and acne respectively), as shown in table 3 ( $\mathrm{p}<0.05)$. After adjusting for overweight classification according to WC, the increased likelihood of overweight perception persisted both among girls reporting breast growth and girls reporting acne $(\mathrm{p}<0.05)$. No significant interaction factor was found between breast growth and WC or between acne and WC; the interaction factor was therefore omitted from further analysis.

In order to compare the impact of emergence of breast growth or acne among nonoverweight and overweight girls, odds ratios for these groups were calculated separately and presented in table 4 . Table 4 shows that the likelihood of overweight perception was significantly increased, especially among non-overweight girls who reported apparent breast growth $(\mathrm{p}<0.01)$.

Table 3. Logistic univariate regression model predicting odds ratios (OR), 95\% confidence intervals (CI), and significance of perceived emergence of each of the secondary pubertal characteristics, for overweight perception. In a multiple regression model, the OR for each of the characteristics of overweight perception is predicted and adjusted for overweight based on WC.

\begin{tabular}{|c|c|c|c|c|c|}
\hline \multirow[b]{2}{*}{$\begin{array}{l}\text { Perceived emergence of } \\
\text { secondary pubertal } \\
\text { characteristics }\end{array}$} & \multicolumn{3}{|c|}{ OR for overweight perception } & \multicolumn{2}{|c|}{$\begin{array}{c}\text { OR adjusted for } \\
\text { overweight based on WC }\end{array}$} \\
\hline & $\begin{array}{l}\text { OR when } \\
\text { perceived } \\
\text { "not started" }\end{array}$ & $\begin{array}{l}\text { OR when } \\
\text { perceived } \\
\text { "started" }\end{array}$ & $\begin{array}{l}\text { CI perceived } \\
\text { "started" }\end{array}$ & $\begin{array}{l}\text { OR when } \\
\text { perceived } \\
\text { "started" }\end{array}$ & $\begin{array}{l}\text { CI perceived } \\
\text { "started" }\end{array}$ \\
\hline Breast growth $(n=220)$ & 1.00 & $2.83^{*}$ & $1.51-5.31$ & $2,73^{*}$ & $1.36-5.47$ \\
\hline Acne $(n=203)$ & 1.00 & $2.56^{*}$ & $1.42-4.60$ & $2.02 *$ & $1.07-3.82$ \\
\hline Pubic hair growth $n=214$ ) & 1.00 & 1.33 & $0.73-2.42$ & 1.37 & $0.70-2.66$ \\
\hline Growth spurt $(\mathrm{n}=173)$ & 1.00 & 1.30 & $0.72-2.35$ & 1.04 & $0.55-1.99$ \\
\hline Menstruation $(\mathrm{n}=220)$ & 1.00 & 1.55 & $0.88-2.74$ & 1.45 & $0.77-2.73$ \\
\hline
\end{tabular}

Table 4. Logistic univariate regression model predicting odds ratios (OR), 95\% confidence intervals $(C I)$, for overweight perception among non-overweight and overweight girls, respectively, who reported breast growth and acne. Overweight classification is based on WC.

\begin{tabular}{l|cccc}
\hline $\begin{array}{l}\text { Perceived } \\
\text { appearance of: }\end{array}$ & \multicolumn{2}{|c}{$\begin{array}{c}\text { OR (95\% CI) for overweight } \\
\text { perception among } \\
\text { Non-Overweight girls }\end{array}$} & $\begin{array}{c}\text { OR (95\% CI) for overweight } \\
\text { perception among } \\
\text { Overweight girls }\end{array}$ \\
\hline Breast growth & $\mathrm{n}=170$ & $3.57(1.47-8.66) * *$ & $\mathrm{n}=50$ & $1.94(0.51-7.47)$ \\
Acne & $\mathrm{n}=155$ & $2.02(0.95-4.33)$ & $\mathrm{n}=48$ & $1.81(0.47-6.97)$ \\
\hline$* * p<0.01$
\end{tabular}




\section{Body perception in relation to parental SES, gender and age}

The level of parental education and occupational status were not independent of one another. The Spearman correlation coefficient between level of education and occupational status among mothers was $0.61(\mathrm{p}=0.042 ; \mathrm{n}=299)$ and among fathers $0.56(\mathrm{p}=0.045 ; \mathrm{n}=284)$. Within families, between mothers and fathers, the correlation coefficient for level of parental education was 0.42 $(\mathrm{p}=0.053 ; \mathrm{n}=292)$ and for parental occupational status $0.35(\mathrm{p}=0.056 ; \mathrm{n}=306)$.

Only among boys $<13$ years (mean $=10.4$ years, $n=65)$ did age and gender-specific analyses show an association between low parental SES, particularly low maternal SES, and higher prevalence of overweight/obesity $(\mathrm{p}<0.01)$. When assessing the relationship between parental SES and IsoBMI and WC respectively, the findings were similar regarding the previous association between overweight/obesity and maternal SES in boys younger than 13 years. Among boys $\geq 13$ years $($ mean $=15.1$ years, $n=39$ ), only an association between a high mean IsoBMI and WC and low level of paternal education was found ( $\mathrm{p}<0.05$ ). In girls, only among those $\geq 13$ years $($ mean $=15.0$ years, $n=74)$, were high mean IsoBMI and WC found to be associated with low level of paternal occupational status $(\mathrm{p}<0.05)$, but not with paternal educational status. No significant gender differences in prevalence of overweight/obesity were found according to either IsoBMI or WC.

Concerning perception of overweight, differences were found in age and gender, but not in relation to social inequality. A logistic regression model predicted that girls $(n=157)$ were at a 2.65 (CI 1.3-5.4; $\mathrm{p}<0.01)$ times higher risk for perception of overweight than boys $(n=104)$. We therefore present separate regression models for boys and girls that provide odds ratios (OR) for determinants for perception of overweight in table 5. For boys, only measured overweight according to either IsoBMI or WC was a significant determinant for perception of overweight ( $\mathrm{p}<0.019$. Adjusting for age $\geq 13$ years showed that IsoBMI and WC were still significant determinants. Separate regression models for measured overweight among boys younger and older than 13 years, respectively, revealed that the model could not be run for boys $\geq 13$ years because of an empty cell in the model, implying the exact OR to be zero. Among younger boys, the OR for perception of overweight increased for both measured overweight according to IsoBMI and to WC compared with all boys $(\mathrm{p}<0.01)$. Among boys, measured overweight according to WC was no longer a significant determinant for perception of overweight after 


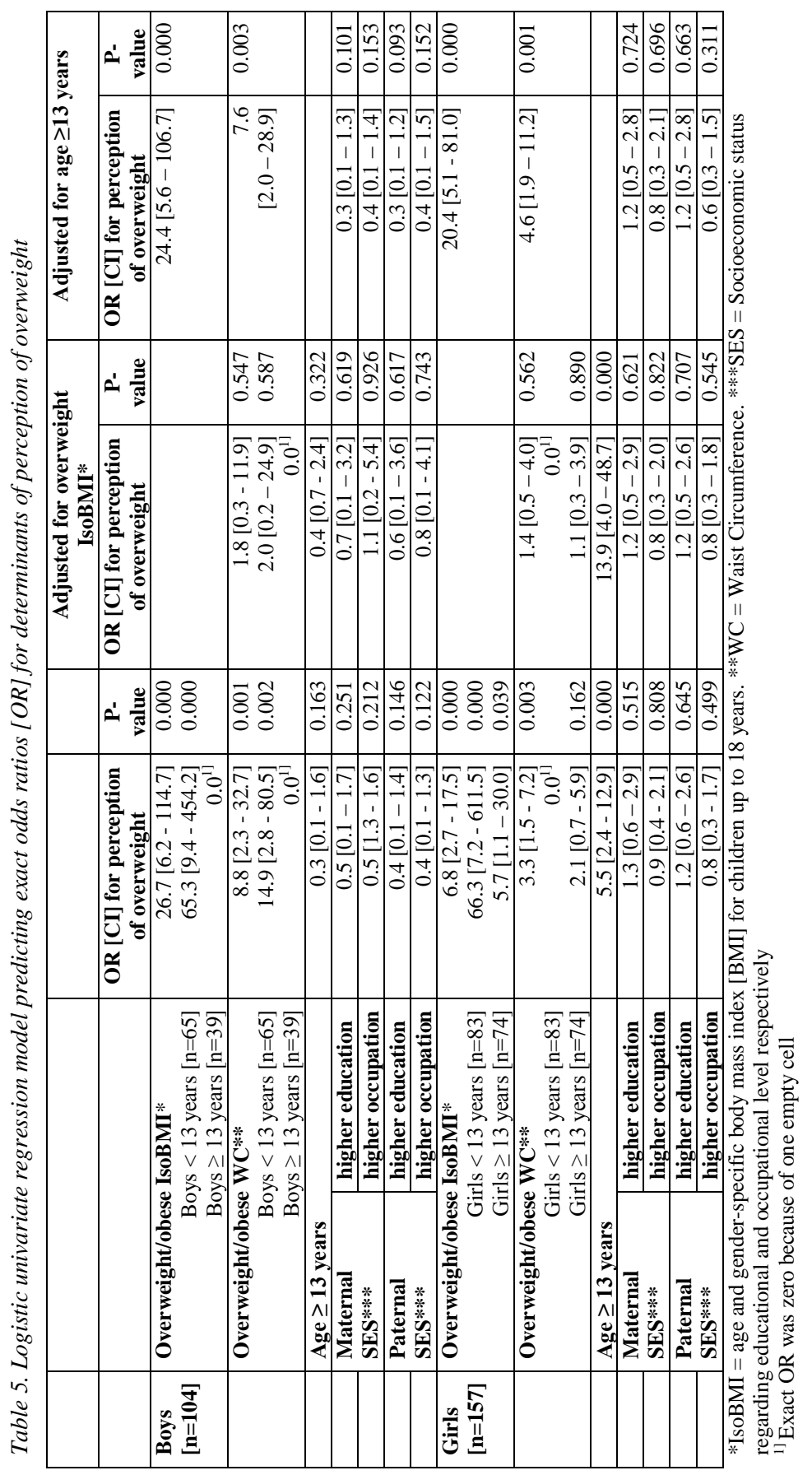


adjusting for measured overweight according to IsoBMI. Neither age nor parental SES was found to be related to perception of overweight in boys.

Among girls, measured overweight according to IsoBMI and WC, as well as age $\geq 13$ were significant determinants for perception of overweight $(\mathrm{p}<0.01)$. Similarly to the boys, the OR for perception of overweight when measuring overweight according to WC was no longer significant when adjusted for overweight according to IsoBMI. However, the OR for perception of overweight increased among girls who were overweight according to IsoBMI and WC when adjusted for age and showed that measured overweight was a stronger determinant in the younger age group, $<13$ years $(\mathrm{p}<0.01)$. Age-specific models for girls confirmed this finding for perception of overweight in the presence of measured overweight according to IsoBMI with ORs of 66.3 (CI 7.2-611.5; $\mathrm{p}<0.001$ ) and 5.7 (CI 1.1-30; $\mathrm{p}<0.05$ ) for the younger and older girls, respectively ( $\mathrm{p}<0.05)$. Age $\geq 13$ years as a single determinant for perception of overweight was found to be significant and the OR that age $\geq 13$ years influences perception of overweight increased significantly when adjusted for measured overweight according to IsoBMI ( $<<0.001)$. As in the case of boys, parental SES was not a significant determinant for perception of overweight in girls.

The results described above relate to the prevalence of misconception 1 (perception of overweight despite measured non-overweight) among boys and girls. Table 6 shows that the prevalence of misconception 1 was significantly higher among girls $\geq$ age 13 , who more often perceived themselves as overweight despite measured non-overweight according to IsoBMI and $\mathrm{WC}$, than did boys of any age $(\mathrm{p}<0.05)$ and girls < age $13(\mathrm{p}<0.01)$. No significant gender or age differences were found for misconception 2 , where overweight was measured, but not perceived.

Table 6. Prevalence of misconception 1 and misconception 2 for boys and girls respectively

\begin{tabular}{|c|c|c|c|c|c|c|c|c|c|}
\hline & \multirow[b]{2}{*}{$\begin{array}{c}\text { All boys } \\
{[n=98]}\end{array}$} & \multirow[b]{2}{*}{$\begin{array}{l}\text { All girls } \\
{[n=141]}\end{array}$} & \multirow[b]{2}{*}{ P-value } & \multicolumn{3}{|c|}{ Boys } & \multicolumn{3}{|c|}{ Girls } \\
\hline & & & & $\begin{array}{c}<13 y \\
{[n=62]}\end{array}$ & $\begin{array}{c}\geq 13 y \\
{[n=34]}\end{array}$ & $P$ - value & $\begin{array}{c}<13 y \\
{[n=74]}\end{array}$ & $\begin{array}{c}\geq 13 \text { y } \\
{[n=67]}\end{array}$ & P-value \\
\hline \multicolumn{10}{|l|}{ Misconception $1^{1]}$ : } \\
\hline IsoBMI* & $4.1 \%$ & $16.3 \%$ & 0.003 & $3.2 \%$ & $5.9 \%$ & 0.533 & $1.4 \%$ & $32.8 \%$ & 0.000 \\
\hline $\mathbf{W C} * *$ & $4.1 \%$ & $11.5 \%$ & 0.043 & $3.2 \%$ & $5.9 \%$ & 0.533 & $0.0 \%$ & $24.2 \%$ & 0.000 \\
\hline \multicolumn{10}{|l|}{ Misconception $2^{2]}$ : } \\
\hline IsoBMI* & $6,1 \%$ & $6,4 \%$ & 0.935 & $4.8 \%$ & $8.8 \%$ & 0.440 & $9.5 \%$ & $3.0 \%$ & 0.116 \\
\hline $\mathbf{W C * *}$ & $16.3 \%$ & $20.9 \%$ & 0.381 & $17.7 \%$ & $14.7 \%$ & 0.703 & $26.0 \%$ & $15.2 \%$ & 0.115 \\
\hline
\end{tabular}

${ }^{1]}$ Misconception 1: Perception of overweight without being measured as overweight/obese according to IsoBMI and WC respectively. ${ }^{2]}$ Misconception 2: Perception of non-overweight despite being measured as overweight/obese according to IsoBMI and WC respectively *IsoBMI = age and gender-specific body mass index [BMI] for children up to 18 years. $* * W C=$ Waist Circumference 


\section{Body perception in relation to eating habits}

Among both boys and girls, the strongest risk factor for engaging in dieting behaviours was perception of overweight, which persisted after adjusting for being overweight and for age $(\mathrm{p}<0.01)$. Table 7 presents the ORs for dieting and skipping breakfast for boys and girls, respectively, when overweight is perceived or measured. Among girls, the risk of dieting increased significantly with perception of overweight and persisted after adjusting for measured overweight according to IsoBMI and WC, as well as for age $\geq 13$ years. Moreover, measured overweight according to IsoBMI was an independent risk factor for girls to be on a diet $(\mathrm{p}<0.05)$, since it persisted even after adjusting for other factors. Feeling the need to lose weight increased significantly with perception of overweight among both girls and boys $(\mathrm{p}<0.01)$, even after adjusting for other factors $(\mathrm{p}<0.01)$. Measured overweight according to IsoBMI among boys $(\mathrm{p}<0.01)$ and $\mathrm{WC}$ among girls $(\mathrm{p}<0.01)$ were other significant independent gender-specific risk factors. The risk of skipping breakfast increased with perception of overweight only among girls $(p<0.01)$ and persisted after adjusting for other factors $(p<0.05)$.

Skipping breakfast was found to be related to more negative body perception and to higher BMI in both boys and girls $(\mathrm{p}<0.05)$. Skipping breakfast was also associated with unbalanced gender-specific food consumption patterns as depicted by the highlighted cells in table 8 . Among boys, breakfast consumption correlated positively with consumption of lunch and negatively with consumption of sweets on weekdays $(\mathrm{p}<0.05)$. In boys, lunch consumption was, in turn, positively related to consumption of dinner and to snacking behaviour $(p<0.05)$. Snacking correlated positively with fruit consumption $(\mathrm{p}<0.01)$, which in turn correlated positively with consumption of vegetables $(\mathrm{p}<0.01)$. Consumption of vegetables was negatively related to consumption of sweets and sugary drinks $(\mathrm{p}<0.05)$, while consumption of sweets showed a strong positive correlation with consumption of sugary drinks for boys $(\mathrm{p}<0.01)$. 


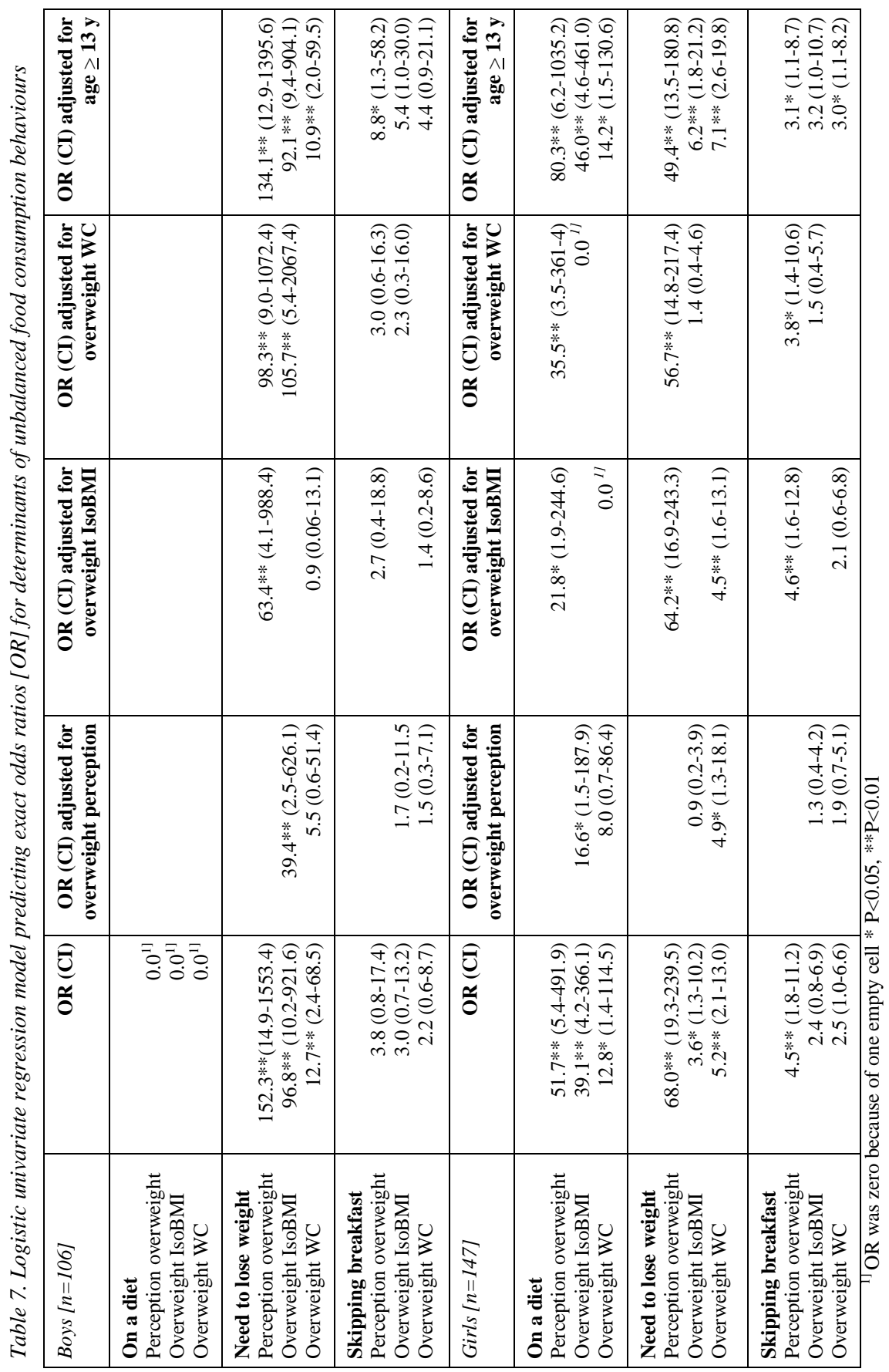


Among girls, consumption of breakfast was positively associated with consumption of lunch and dinner $(\mathrm{p}<0.01)$. Moreover, breakfast consumption showed a direct positive correlation with consumption of fruits and vegetables, and a negative correlation with consumption of sweets and sugary drinks $(\mathrm{p}<0.05)$. Lunch consumption was, in turn, positively related to consumption of dinner and snacking behaviour $(\mathrm{p}<0.05)$. For girls, dinner consumption, snacking behaviour and consumption of vegetables correlated positively with each other $(\mathrm{p}<0.05)$, while snacking behaviour and consumption of sweets showed a negative association $(\mathrm{p}<0.05)$. We found that consumption of fruit was positively related to consumption of vegetables, while consumption of candy was positively related to consumption sugary drinks for girls $(\mathrm{p}<0.01)$.

Unbalanced food consumption behaviours such as dieting and skipping breakfast were found to be more common among adolescents than among younger boys and girls $(\mathrm{p}<0.05)$.

Table 8. Spearman's rho coefficients for correlations within food consumption behaviours, as well as food consumption patterns with highlighted cells indicated as being significant for boys and girls respectively

\begin{tabular}{|c|c|c|c|c|c|c|c|}
\hline & \multicolumn{7}{|c|}{ Boys $(n=100)$} \\
\hline & Breakfast & Lunch & Dinner & Snacking & Fruit & Vegetables & Candy \\
\hline Lunch & $0.221 *$ & 1.000 & & & & & \\
\hline Dinner & 0.113 & $0.252 *$ & 1.000 & & & & \\
\hline Snacking & 0.122 & $0.203^{*}$ & 0.118 & 1.000 & & & \\
\hline Fruit & 0.009 & 0.139 & 0.092 & $0.321 * *$ & 1.000 & & \\
\hline Vegetables & 0.197 & 0.131 & 0.030 & 0.131 & $0.436^{* *}$ & 1.000 & \\
\hline Candy & $-0.208 *$ & -0.003 & -0.001 & -0.110 & -0.159 & $-0.228^{*}$ & 1.000 \\
\hline \multirow[t]{3}{*}{ Sweet drinks } & -0.188 & 0.171 & 0.028 & -0.126 & -0.180 & $-0.225^{*}$ & 0.440 ** \\
\hline & \multicolumn{7}{|c|}{ Girls $(n=146)$} \\
\hline & Breakfast & Lunch & Dinner & Snacking & Fruit & Vegetables & Candy \\
\hline Lunch & $0.575^{* *}$ & 1.000 & & & & & \\
\hline Dinner & $0.235^{* *}$ & $0.201 *$ & 1.000 & & & & \\
\hline Snacking & 0.165 & $0.182 *$ & $0.368 * *$ & 1.000 & & & \\
\hline Fruit & $0.191 *$ & 0.117 & 0.090 & 0.145 & 1.000 & & \\
\hline Vegetables & $0.174 *$ & 0.119 & $0.261 * *$ & $0.266^{* *}$ & $0.455^{* *}$ & 1.000 & \\
\hline Candy & $-0.176^{*}$ & -0.092 & -0.062 & $-0.179 *$ & -0.032 & -0.135 & 1.000 \\
\hline Sweet drinks & $-0.173 *$ & 0.143 & 0.042 & -0.107 & 0.007 & -0.033 & $0.292 * *$ \\
\hline
\end{tabular}

$* \mathrm{P}<0.05, * * \mathrm{P}<0.01$ 


\section{Discussion}

\section{Balancing body perception...}

Balancing body perception during growth and development is essential for young people because it is associated with health and health behaviours in both the short- and long-term (72). Perception of the body and its development plays an important role in self-evaluation, mental health and psychological well-being $(87,88)$. Body perception is defined here as the individual's assessment of the physical aspects of the body and the extent to which this assessment is accurate (55). Balancing body perception, as discussed in this thesis, therefore entails understanding the aspects involved when children and adolescents assess their physical body appearance. At the same time, their body perception should be considered in relation to actual and relevant physical measurements in order to evaluate the accuracy of their assessment and the consequences for health and health behaviours.

\section{...with actual body measures}

Our results showed that perception of overweight was associated with actual overweight according to both IsoBMI and WC, but only among younger girls and boys. Also, the prevalence of overweight according to IsoBMI was found to be $14 \%$ among Swedish boys based on both measured IsoBMI in our study and self-reporting in the HBSC study (82). Physical measurements such as weight and BMI are often used as standard indicators since they are related to health outcomes such as overweight and other weight-related diseases. The international classification of overweight according to BMI is used by health professionals worldwide to evaluate health risks in children and adolescents (17). Studies on body perception using body silhouettes are also often related to BMI classification (89). Misconception 2, in which overweight is underestimated, was not found among either boys or girls in our study. So, at least among boys and younger girls, our results confirm that a strong predictor for body dissatisfaction is overweight prevalence according to BMI $(16,90,91)$.

Meanwhile, among adolescent girls, this thesis reveals a discrepancy between body perception and classification according to IsoBMI, despite awareness of body size, as noted in self-reports on height and weight among Finnish girls. We found underestimation rather than overestimation of weight among non-overweight and overweight girls, indicating a lower prevalence of overweight when using the self-reported data to calculate BMI compared with the 
actual data from measured height and weight. Accordingly, the prevalence of overweight according to IsoBMI based on self-reports in the HBSC study was 9\% among Swedish girls and therefore lower indeed, compared with the $15 \%$ based on measured IsoBMI found in our Swedish study (82). The use of self-reported height and weight when assessing perception of body size in girls would suggest that the gap between actual overweight prevalence and perception of body size as being overweight is even larger than we found in our studies using measured height and weight. The incongruence between body perception and measured body size in girls, particularly in older age groups, was confirmed by our Swedish study, which shows an increased OR for perception of overweight for girls age $\geq 13$ when adjusted for measured IsoBMI, as well as by the high prevalence of misconception 1 (feeling too fat despite measured non-overweight) among girls $\geq$ age 13. The weak agreement between subjective body perception and objective definitions among girls could be due to the less well-defined cut-off points for BMI in adolescents than in adults, since they increase with age and vary with gender, stage of pubertal maturation and body composition $(5,19,92)$. The fact that maternal perception did not show a comparable overestimation of their daughters' body size in relation to BMI may support such an explanation, assuming that mothers take growth and development during puberty into account in their assessments $(93,94)$. Many girls tend to consider themselves to be fat even when they are not overweight according to their BMI. And certainly, both fat and lean components of body mass must be considered when interpreting BMI $(18,20,95)$.

In relation to $\mathrm{WC}$, we found that fewer girls expressed body dissatisfaction in terms of regarding themselves as too fat when such was not the case. This finding suggests that girls rely more on WC than BMI when forming their body perception, possibly because WC is more clearly related to abdominal fat and changes in body shape at different ages. The focus on body parts other than the parameters of weight and height and body shape may reflect current physical ideals, as suggested by other studies $(96,97)$. Bergström et al. found that adolescents (without anorexia nervosa) overestimated their body size, particularly at the waist, buttocks and thighs (96). Rhodes et al. (98) showed that obese women with prominent body fat distribution concentrated in visible areas such as the face, chest, and waist, overestimate their body size and feel heavier than they actual are. It is not unlikely that WC, as a characteristic of body shape rather than body size, reflects the 'normal' body shape that adolescent girls in Finland relate to and use to assess body size. Evaluation of the accuracy of body perception among children and 
adolescents should therefore relate to $\mathrm{WC}$, since it seems to be a more relevant body measure than BMI. Furthermore, WC, like BMI, is related to health outcomes such as overweight and other weight-related diseases $(26,27)$.

\section{...with body changes during puberty}

We found that female pubertal characteristics obvious to others, such as breast growth and acne, increase the likelihood of overweight perception, especially in non-overweight girls. In addition, girls who perceived themselves as overweight did in fact have a larger WC and hip circumference, both of which are important visible measures of female body fat distribution. Furthermore, we found a significantly higher WHR among girls who perceived themselves as overweight, indicating that the relatively higher fat deposition in the abdominal region combined with a less "pear-shaped" body play an important role in perception of overweight among girls, as found by Thoma et al. (97). Our finding that non-overweight girls were also likely to perceive themselves as overweight supports the contention that visible physiological changes affect body perception in girls $(99,100)$. The physical changes in body fat distribution and breast growth are more obvious to everyone in non-overweight girls. Breast growth in particular, which girls may initially experience as positive, can become distressing later in the developmental process, since it is associated with the characteristic female accumulation of body fat, not just around breasts, but throughout the body in general (36). The fact that self-reports regarding stage of breast development had no missing values (“I don't know) in contrast to the number of missing values concerning stage for growth spurt, suggests that school-aged girls are themselves aware of the process of breast development and are therefore easily able to respond to this item.

This increase in body fat that naturally accompanies puberty in girls conflicts with stereotypes of the ideal female body $(1,101)$. Girls in puberty have therefore been shown to develop a negative perception of their body, which was also confirmed by our results with a high prevalence of misconception 1 . On the contrary, boys undergoing puberty naturally become more muscular and develop broader shoulders following their growth spurt (30), both factors contributing to the positive ideal of the male body $(54,102)$. Boys $\geq 13$ years may therefore develop a more positive self-image with age and pubertal development, which might explain the relative lack of misconception 1 (feeling fat despite measured non-overweight) among boys.

Adolescence is a period of rapid physiological change, so it is not surprising that the majority of disturbances in body perception are found during this period $(1,32)$. Several studies 
show that individuals who mature early or more rapidly tend to have more subcutaneous truncal fat than their same-aged peers $(40,42)$. The timing of pubertal maturation in girls has been shown to influence body perception where girls maturing early more often reported feeling too fat (46). However, in our studies we could not confirm this as we did not find significant results for overweight perception related to age at menarche, neither for the likelihood of overweight perception when started menstruating. Furthermore, our studies with cross-sectional design are unable to answer whether the higher amount of abdominal fat is a cause or an effect of the stage of female pubertal development $(35,103)$.

When discussing pubertal development it is important to note the secular trend in pubertal timing over the past century. Age at menarche decreased dramatically during the first half of the twentieth century in western nations. From 1960 onwards, the trend towards earlier onset of menarche has slowed and actually reversed in some societies (104). However, modern studies found significantly earlier breast development among girls who were born more recently (105107). Thus, a secular trend towards earlier breast development may raise some alarm, considering the association between breast development and inappropriate overweight perception shown by our study.

\section{...with eating habits}

Perception of overweight was found to be the strongest risk factor for dieting behaviours in both girls and boys; this factor persisted after adjusting for actual overweight and age, as has also been found in other studies $(72,108)$. Moreover, body dissatisfaction was associated with less frequent consumption of breakfast in both sexes. In line with other studies, eating habits seemed to have stronger associations with body satisfaction than with actual body weight, especially in girls (59, 74).

Girls who wished to be thinner skipped breakfast and other meals more often than girls who were satisfied with their bodies. The ideal of a thin body commonly shared by girls makes them more likely to engage in various forms of weight reduction behaviour, including skipping breakfast $(72,76)$. Both higher WC and BMI were shown to be associated with less frequent consumption of breakfast in girls, which implies that skipping breakfast represents an attempt to lose weight, as also found in other studies $(59,70)$. Furthermore, as shown earlier, we found that girls were more likely than boys to unrealistically perceive themselves as too fat and to feel the need to lose weight (109). Moreover, overweight according to WC, as an indicator of abdominal 
fat, was strongly associated with weight reduction behaviour in girls, and, at the same time with body perception. The physical development that accompanies pubertal maturation, with an increase in body fat, might therefore explain why weight loss behaviour was more prevalent among the older group of girls $(16,82)$.

Among boys, in contrast to girls, overweight according to IsoBMI, but not to WC, was found to be another independent risk factor that motivated a need to lose weight. This could imply that dieting or weight reduction behaviour among boys may result from body perception based on actual high weight and BMI, as confirmed by the lack of misconception 1 (feeling too fat despite measured non-overweight) among boys. Another finding in boys was that less frequent breakfast consumption was associated with high BMI, but not with high WC. Other cross-sectional studies also found an inverse relationship between breakfast consumption and BMI, including analysis of data from the 41 countries participating in the HBSC study (2). At the same time, in boys, high BMI and WC were also associated with lower consumption of vegetables and higher consumption of sugary drinks, lending credence to the idea that eating habits are the cause, rather than the effect, of body size.

Even though breakfast consumption was found to be associated with other eating habits in both boys and girls, the relationship between consumption of breakfast and other foods differed between boys and girls. In boys, a correlation chain was found, where consumption of breakfast was related to lunch, which in turn was related to snacking, and ultimately to fruit and vegetable consumption. The latter group, in turn, was inversely related to consumption of sweets and sugary drinks. Such food consumption patterns among boys have also been observed in other studies $(68,79)$. In contrast, among girls, breakfast consumption varied directly with consumption of lunch, dinner, fruits and vegetables, and inversely with consumption of sweets and sugary drinks. Other studies suggest that the food consumption patterns found among girls may be attributable to higher weight and health consciousness among girls, who are thus more committed to healthy eating than boys $(71,75,110)$. One hypothesis to explain gender similarities and differences in food consumption patterns might be that the part of the correlation chain found to be similar in both boys and girls could be age- and peer-related, while the pattern of direct correlations seen in girls could be part of dieting behaviour. 


\section{...with influences of parents and peers}

One of our studies found that perceptions of body size as reported by girls vs. their mothers did not agree very well. The girls had a more negative body perception and felt they were fatter than their mothers perceived them to be. However, mothers also perceived their daughters as thinner than the objective classification when girls were found to be overweight, presumably either downplaying or denying the overweight status of their daughters. Since overweight and obesity also entail a subjective, emotional experience of the body, a better understanding of this dimension by healthcare professionals and individuals is an important complement to actual physical measurements when assessing, diagnosing, and treating these conditions (94). The dropout rate in our first study indicated a trend towards non-participation related to the perception of overweight, confirming the importance of the subjective emotional experience. Personal body perception by girls rather than by their parents might therefore be important in prevention and intervention programmes, since adolescence is the prelude to solidifying adult lifestyle and behaviour. Nevertheless, the female desire to be thin reflected in the literature, and shared by both mothers and girls, may have a considerable impact on body perception among girls (111, 112).

It has been suggested that overweight mothers in particular have greater difficulty accurately assessing weight in younger children when using themselves as a reference point ( 9 , 113, 114). Higher prevalence of overweight among parents may therefore affect the motivation of their children to avoid further weight gain (114). The greatest maternal misperceptions of weight status among children were observed in children categorised as overweight/obese (113). One study shows that parents believe that being "chubby" at a young age is "cute" and that overweight in childhood is not a problem prior to adolescence (115). Moreover, research suggests that some physicians circumvent identification of childhood overweight and therefore do not always inform mothers that their children's weight is of concern (116).

Among younger children with low SES parents, especially mothers, we found higher prevalence of overweight and obesity, which might be due to lifestyle in addition to hereditary predisposition (114). In families - especially among mothers - with low SES, less emphasis on, as well as limited exposure to, healthy eating habits and physical activity may be important risk factors for children to develop overweight and obesity $(9,65,79)$. In addition, younger children spend more time with their parents, especially their mothers. Parents shape social norms and 
serve as role models for behaviour, and are likely to reflect the values of their social class (117). However, the type and extent of parental influence on the child will vary in accordance with the maturity of the child. Parental influence decreases, while peer influence increases as children grow older, for which reason parents are likely to have a stronger influence on health behaviours in younger children (82). It is well known that girls mature earlier than boys, suggesting that parents have less influence on girls than on boys of similar age. This might explain why we found that social inequality is only an influential factor in younger boys, but not in either younger or older girls.

Among boys $\geq 13$ years, we only found a significantly higher IsoBMI and WC when their fathers had a low level of education. Low SES is associated with an increase in prevalence of overweight and obesity among adults in developed countries, suggesting that fathers with a low level of education in this study are at increased risk of being overweight themselves due to the social norms and behaviours of their social class. In addition to hereditary factors, adolescent boys may be at increased risk for overweight and obesity by adopting the norms and lifestyle of their fathers when they serve as role models (118).

Eating behaviours such as lower consumption of vegetables, higher consumption of candy and sugary drinks, as well as skipping dinner, may be assumed to relate to peer influence among older adolescent boys. Among girls, skipping breakfast, less snacking and lower fruit consumption were related to higher age. Based on our results, we may infer that fruit consumption, snacking frequency and skipping breakfast might be behaviours attributable to peer influence among adolescent females. While other studies have reported that girls skipped breakfast more often than boys $(68,75)$, we found only age differences within each gender regarding breakfast behaviours, suggesting that skipping breakfast may merely be part of adolescent behaviour. Vereecken et al. (68) also found lower daily breakfast consumption in children older than 11 years, which may be rooted in important changes that accompany adolescence, including greater autonomy and independence in food choices, decreased frequency of family meals and increased peer influence, as well as an increase in dieting behaviour, especially among girls (119). 


\section{Our results in a public health context}

\section{Comparisons over time and across countries}

Comparisons with the WHO HBSC survey confirm the relevance and the duality of the weightrelated public health concerns studied here, by showing the increasing prevalence of overweight and obesity (2), especially among boys, and the even greater increase in body dissatisfaction, not only among girls, but also among boys (108). Compared with the results of the HBSC survey in Finland, girls in our Finnish cross-sectional study showed a lower prevalence of overweight and overweight perception (81). When we analysed drop-out rates in our Finnish study we found that girls who participated only once in the study more often perceived themselves to be overweight or obese than girls who participated all three years, which may in part explain the lower prevalence of overweight and obesity in our findings. In any case, this lower prevalence implies a greater quantitative problem than that emanating from our study population, and that the associations with body measurements and female development found in our study may contribute significantly to understanding weight-related concerns among girls. In addition, results from our Swedish cross-sectional study showed lower overweight perception among boys and girls compared with the Swedish WHO HBSC results despite an increase over time in Sweden (82). The associations between overweight perception and gender, age and eating habits found in our Swedish study underscore the importance of understanding the in fact larger public health concerns regarding body perception than shown here.

However, the prevalence of overweight was higher in our Swedish study compared with the results of the Swedish HBSC survey (82). This discrepancy may be because our studies based BMI on measured height and weight, while the HBSC surveys used self-reported height and weight to calculate BMI, as discussed above (120). Our Swedish findings relate to the prevalence of overweight among boys and girls, and therefore contribute to understanding the associations between body perception and eating habits, although the results must be interpreted with caution when making comparisons with studies using BMI based on self-reported data (120).

The HBSC survey findings confirm that weight reduction behaviour and skipping breakfast are common in young people, especially girls. The prevalence of such behaviours was either similar or lower in both our cross-sectional studies compared with the HBSC results (81, 82). This implies that our results, which explored the associations between body perception and eating habits in relation to actual body measurements, body development, age and gender, can be 
used to gain a deeper understanding of food consumption behaviours during growth and development. The HBSC survey also revealed some interesting findings showing decreased prevalence of weight reduction behaviour and skipping breakfast among girls over time $(81,82)$, a trend also seen in the comparison between our 1997-2000 Finnish girls' cohort and our 2010 Swedish girls' cohort, despite an increase in body dissatisfaction among girls between 2001/2002 and 2009/2010. An analysis of the 2001/2002 HBSC survey showed that young people who do not report their height and weight are more likely to be dieting or to feel the need to lose weight (81). Similar reporting bias could be an explanation for the decrease in weight reduction behaviour seen in our studies. Another explanation may be that the decrease in these behaviours among girls could be associated with the levelling off in the objectively based prevalence of overweight/obesity among girls in Sweden (121) as found by our studies, but further investigation would be needed to better understand these trends.

Based on the relevance of the issues studied, the findings from our cross-sectional studies in smaller populations can contribute to understanding the changes over time and differences across countries as described and discussed in the WHO HBSC surveys (122). Our objective measurements of weight and height in a small population contribute to the further understanding of possible bias associated with the self-reported data collected in the WHO HBSC studies. By including the self-administered female pubertal development scale in addition to age at menarche (84), we add to the understanding of what characteristics in female development are important for body perception and confirm the hypothesised impact of body fat and fat patterning on body perception in adolescent girls (82). Our small study populations allowed us to conduct deeper analyses regarding the associations of body perception and eating habits in relation to actual body measurements, age and gender, as a complement to the large cross-country population used in the WHO survey.

\section{The Östergötland Model for Equity in Health}

The findings described in this thesis should be recognised and discussed as elements of the complex interplay between the individual, societal and environmental factors that determine health in both the short- and long-term. The Dahlgren and Whitehead model for determinants of health (123), used in international and national policy documents since 1991, has recently been developed further into the Östergötland Model for Equity in Health by van Vliet and Kristenson, shown in figure 6 (124). As in the Dahlgren and Whitehead model, the Östergötland model 
presents a social model for health, including both fixed factors such as gender, age and genetics, and potentially modifiable factors at both the individual and societal level. Unlike the Dahlgren and Whitehead model, the Östergötland model for Equity in Health includes both individual socioeconomic status and psychological resources as important determinants for health (124). The model depicts not only how individual and societal factors determine individual health, but also how the health of the individual is crucial for psychological, social-environmental, lifestyle and socioeconomic factors, as well as from the arena perspective and for contributing to a sustainable society.

In this thesis, the Östergötland model can be applied to provide an explanatory framework for the identified associations, putting them into a broader public health context, and creating an opportunity to develop a more multifaceted understanding of health in young people. The health outcomes studied here were measured overweight and obesity according to BMI and WC, body perception, and self-reported female pubertal development, by gender and age - in the context of our studies, children and adolescents. The associations studied can be viewed as determining factors within the layers socioeconomic status, lifestyle, social environment and within the circle of the individual's health outcome.

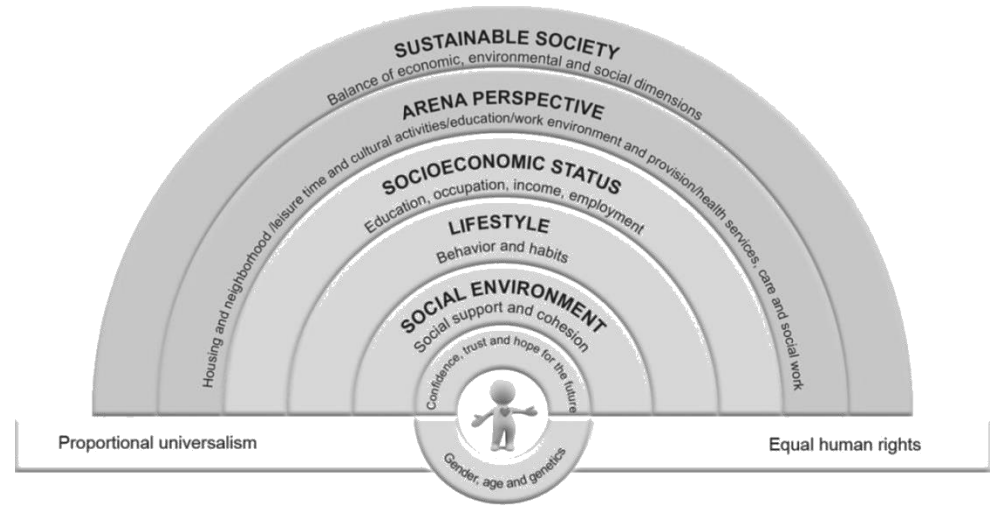

Figure 6. "The Östergötland model for equity in health - interaction between individual, environment and society" by van Vliet and Kristenson, 2014 (124), based on the model for the determinants of health by Dahlgren and Whitehead (123)

Using the Östergötland model to explain the associations found, it is suggested that psychological resources as self-confidence, trust in others and hope for the future are crucial mediating factors 
for these associations (see figure 6). For example, body image is described elsewhere as a psychological construct that is part of self-image and related to self-confidence (1). Future research in the field of health and behaviour among young people should include these psychological factors as crucial determining factors for health outcomes, as well as for social support and cohesion.

At the same time, the Östergötland model provides a useful framework for policies, strategies and actions to promote and improve health outcomes such as body perception and overweight among children and adolescents as studied here. This model shows how action can be taken at the individual level by affecting the individual's lifestyle, social environment and psychological resources, as well as at the societal level, specifically by creating health-promoting conditions in the arenas where young people are found. The age, gender and SES differences found in our studies highlight the need for proportional universalism, which means that interventions should be universal, but allocated in proportion to differences in physiology, psychology, needs and conditions.

\section{Strengths, limitations and lessons learned}

This thesis focuses on self-reported perception of the body. Self-reported body perception is considered to be a strength here since perception of overweight is an important determinant for actual and future weight and health behaviours $(59,82)$. Our studies compared self-reported perception of overweight with both actual body size according to anthropometric measurements and with the results of the international WHO HBSC study carried out the same years $(81,82)$. The latter confirmed the importance of comparing physical measurements with self-reported weight and height to understand the possible bias in self-reporting, especially among girls (120).

Regarding stage of pubertal maturation, we preferred self-assessment of these characteristics over the more objective Tanner scale, which involves actual measurements, because we feel that self-assessment of different body sites and female characteristics relates better to body perception. Moreover, a self-rating scale may better reflect stage of body consciousness.

The inclusion of boys in our Swedish study is also a clear strength, since little is known about their body perception and even less regarding associations with their eating habits. Furthermore, what we learned about boys from the comparison with girls also contributed to our understanding of how girls perceive their bodies during growth and development. 
Body perception in both boys and girls was measured with a single-item categorical response, which may be imprecise. However, the use of the item as formulated in the HBSC study, which is conducted every four years in most European countries, allowed us to make international comparisons, as well as certain generalisations from our results despite our relatively small study populations $(81,82)$. The single-item measure regarding body perception may also be a strength in our study since it has been shown to roughly identify unhealthy perceptions and resultant eating habits. Moreover, a single-item approach to evaluation of body perception can easily be assessed both on the individual level and in large-scale screening programmes, and may thus be of significant value for preventing unhealthy eating habits and resultant ill health and disease.

This thesis describes time-lag results over many years and from two different countries. One strength is the comparison with the results of the WHO HBSC survey over the same time period in both countries, with the potential for further complementary analyses, only feasible in small populations.

This study analysed only cross-sectional data from boys and girls, suggesting important results on associations between variables and comparisons between groups, although due to the nature of the study design, our results cannot be used to identify any cause-effect chains. One limitation of this thesis on body perception and development is the lack of longitudinal data, particularly on girls before they enter puberty and throughout the maturation process, which would allow the study of causes and effects of body fat distribution at different pubertal stages. The small study population limited classification into groups and comparisons at multiple levels, for which reason the results should be interpreted with caution.

In order to better understand the developmental pathways and determining factors towards overweight and overweight perception, as well as to be able to intervene in these processes by empowering children and adolescents, future studies are needed. Future studies should include active participation by the young people themselves in study design and discussions of outcomes, in order to achieve better understanding of the factors that are important and relevant for children and adolescents during their development, and of course, to increase the participation rate and interest in the study. Future studies should be based on both qualitative and quantitative data, and preferably collect longitudinal data during the developmental years from childhood to late adolescence that are so critical for future health. 


\section{Practical implications}

The results presented in this thesis might become a useful basis for health education in schools and interventions within the various arenas where children and adolescents are found. Improved understanding of the risk factors associated with the natural processes of growth and development, which may lead to weight-related health problems later in life, is important for prevention and treatment of problems, diseases and disorders. Successful prevention programmes at the societal and the environmental levels need to integrate biological, psychological and sociocultural approaches that take individuals and their environments into account. Gender, age and SES are important factors in social differentiation that must be addressed when designing successful general and targeted interventions.

Concrete proposals for action resulting from our cross-sectional studies to be implemented by schools and healthcare services:

- To benefit the future health and health behaviours of schoolchildren, we wish to emphasise the concept of body perception as a pathway towards a better understanding of the changes that normally accompany growth and development. We suggest educational interventions to improve understanding of the physical changes that normally accompany growth and pubertal development, and how children and adolescents perceive these bodily changes, aimed at the boys and girls, their parents, schools, and healthcare services.

- In addition to BMI, we suggest measuring WC as a relevant measure in children and adolescents in schools and in the medical setting to minimise the gap between measured and perceived body size. In adults, WC is the most recently adopted indicator of weightrelated health problems used by health professionals, while body perception has been found to be an important target of intervention to improve subjective health in adolescence. WC in adolescents, used by both health professionals and individuals, could serve as an additional objective measurement of body size and as a common target for intervention. This implies guidelines and age-adjusted cut-off points for WC in adolescents to identify abdominal overweight and related health risks at an early stage. 
- We suggest using self-reported breast growth as an indicator of accumulation of body fat in females, along with age at menarche, as measurements for female pubertal development, in order to address the risk for overweight perception in girls.

- We suggest using self-reports on breakfast consumption to assess the risk for other unhealthy eating habits and to help prevent overweight and obesity.

- When planning interventions to prevent overweight and obesity among children and adolescents, parental SES, along with age and gender-specific differences in social norms and perception of body weight status should be taken into account. 


\section{Conclusions}

The way individuals perceive their bodies during growth and development reflects a complex gender-specific balance between body measures such as weight, BMI and WC, and body changes during pubertal maturation on the one hand, and eating habits and parental and peer influences on the other.

Paper I: WC, more so than BMI, reflects self-perception of body size, possibly due to its relationship to abdominal fat at different ages. For effective prevention and treatment programmes for weight-related health problems among adolescent girls, we recommend measuring WC to diminish the discrepancy between measured and perceived body size.

Paper II: Girls, especially non-overweight girls, may confuse the natural physical changes accompanying female pubertal development with being overweight. It is therefore important to consider self-perception of the body as a whole in addition to objective assessment of the body.

Paper III: Low parental SES, especially among mothers, is associated with overweight among boys in childhood, while low paternal SES is associated with anthropometric measures in adolescence among both boys and girls. Age and gender differences were related to perception of overweight, but social inequality was not.

Paper IV: Body perception is an important determinant for dieting behaviours and skipping breakfast during adolescence, not just in girls, but also in boys. Body perception and consumption of breakfast can serve as indicators to identify and support children and adolescents at risk for unhealthy food behaviours during adolescence and tracking into adulthood. 


\section{Acknowledgements}

After working on my PhD studies for almost 20 years, it is with great pleasure and confidence that I present this thesis that has been refined and reinforced over the course of my life during these years. It all started when I, originally Dutch, moved to Scandinavia, where I lived first in northern Finland and later in Sweden. I became mother to Frank and bonus parent to Alice, who have taught me so much while growing up into lovely adolescents. I met many interesting people who have influenced, inspired and encouraged me. My experience as a dietician in primary care, research strategist at the county level, chief of staff for the department of public health and director of public health in the Region of Östergötland have all contributed to the process. Without these experiences, personal development and, in particular, all people I met, this thesis would not have been the same.

First of all, I would like to express my deepest gratitude to all of the children, adolescents and parents who participated in the studies in Finland and in Sweden - thank you for answering the questionnaires and for allowing me to use your data. I am very grateful to the participating schools and the school health nurses who collected the data, for all your time and effort.

I would like to thank Professor Leena Räsänen, my main supervisor for my studies in Finland, for your enthusiasm and support, as well as sharing your knowledge in research design and nutrition with me. In 1996, you found a science project in Finnish Lapland that I called ANANAS (Adolescent girls' Nutrition and lifestyle, AN Arctic Study) interesting enough to get me started as a PhD student. Even after I moved my studies to Sweden, you stayed in contact with me and became my co-supervisor. You always seemed happy to hear from me - even after an interval of several years. I would particularly like to thank you for believing in me throughout this process. Thanks also to Maria Jokinen, Suvi Ahonen and Satu Forsman, students at the division of nutrition at Helsinki University at the time of data collection in Finland, for assisting me in the language, measurements and coding, while providing pleasant companionship.

I am extremely grateful to Professor Nina Nelson, who had the courage to "inherit" me and to become my main supervisor for my studies in Sweden. Thank you for encouraging me to continue my Finnish studies by including essential parts of my Finnish ANANAS in VäxUPP (Växjö UtomhusPedagogik-Projekt), Sweden. I would like to thank you, Nina, for your infinite patience, feedback and scientific guidance during the Swedish part of my studies. Without your 
knowledge, experience and help, my interpretations would have been less scientific, and probably quite hard for others to follow and understand. I would like to thank my co-authors Professor Per A. Gustafsson, Associate Professor Karel Duchen, and Dr Elin Allansson Kjölhede for critically reviewing the manuscripts included in this thesis and your supportive comments. I am also very grateful to Susan Larsson and Dr. Charles Larsson for carefully reviewing the language of the original papers and this thesis.

Thanks to Eva Bågenholm, Anders Heijl, Susanne Kvarnström, Lena Lundgren and Annica Öhrn - I appreciate your support and encouragement as my bosses who created conditions that made it possible for me to complete my $\mathrm{PhD}$ studies. Many warm thanks to all my colleagues, co-workers, collaborators and friends for making me feel alive - during and beyond the work with my doctoral thesis - and for giving me energy, happiness, laughter, companionship and friendship. There are too many of you for me to mention everyone, but I hope you know that you are one of the people to whom I am grateful and have been very happy to get to know.

I owe my thanks to my dear parents, who have always let me try my wings, and to my brothers and sisters for being supportive, despite the physical distance. A special thought to my sister Ditta, who showed me by her courage, spirit and hope for the future, not to give up, but to make the best of it, whatever happens in life! I would like to thank Markku and Fredrik, as well as both of your parents, for your love and patience at home during all these years. A special thanks to Alice for showing me, together with Frank, the process of growth and development among girls and boys described in this thesis, in real life.

And last but absolutely not least, my warmest thanks to my son Frank for bringing so much love, joy and happiness into my life. Thank you for always being yourself and for growing up into the person you have become! Since I started this work before you were born, this thesis has been accompanying us during your entire lifetime. Thank you for helping me to put this thesis and my job into perspective through your love, life and needs. Thank you so much for always being there for me, for cheering me up, for your patience and your help. I love you!

\section{Financial support}

The Finnish study was financially supported by the Juho Vainio Foundation and the Finnish Cultural foundation. The Swedish study was funded by the Erik Johan Ljungberg Educational Fund, Medical Research Council of Southeast Sweden (FORSS) and County Council of Region Östergötland. 


\section{Summary in Swedish}

Kroppsfixering bland ungdomar ökar, samtidigt som övervikt och fetma bland barn och unga fortfarande är ett växande folkhälsoproblem. Såväl kroppsfixering som övervikt är förknippade med hälsorisker både på kort och på lång sikt. Syftet med denna avhandling var att studera om ungas upplevelse av att vara för tjock har koppling till faktisk övervikt enligt det professionellt använda måttet Body Mass Index (BMI), eller till hur mycket fett de har på kroppen, främst runt midjan. Mängden och fördelningen av kroppsfett ändras naturligt under puberteten, på olika sätt för flickor och pojkar. Vi har därför även studerat om upplevelsen av att vara för tjock är relaterad till pubertetsutvecklingen. Ett annat syfte var att öka kunskap om hur ohälsosamma matvanor hänger samman med känslan av att vara för tjock och övervikt under barndomen och i tonåren.

Både i Finland och i Sverige ökade antalet överviktiga ungdomar mellan år 2001/02 och 2009/10. Ökningen var störst bland pojkar. Även antalet pojkar och flickor som upplevde sig vara för tjocka ökade mellan 2001/02 och 2009/10. Att känna sig för tjock var vanligast förekommande bland flickor över 13 år. Deras känsla av att vara överviktiga stämde bättre överens med midjeomfånget än med deras BMI. Bröstutveckling och akne under puberteten ökade risken för att flickor upplevde sig som tjocka, framförallt bland flickor som inte var överviktiga. Att känna sig för tjock var den starkaste riskfaktorn för både flickor och pojkar att banta och att inte äta frukost. Att hoppa över frukost var, i sin tur, förknippat med andra ohälsosamma matvanor bland både flickor och pojkar. Utifrån resultaten diskuteras föräldrarnas och kompisarnas inverkan på matvanor, kroppsuppfattning och övervikt under uppväxten.

Sammanfattningsvis visar denna avhandling att ungas upplevelse av att vara för tjocka ter sig olika för flickor och pojkar, vad gäller relation till faktisk övervikt, kroppsfett och -fördelning under pubertetsutvecklingen, ohälsosamma matvanor och påverkan från föräldrar och kompisar. Sett ur ett bredare folkhälsoperspektiv kan den komplexa balansen av faktorer för att uppnå en realistisk kroppsuppfattning bland barn och ungdomar påverkas på såväl individuell nivå, som i de sociala sammanhang och på de arenor där barn och ungdomar befinner sig. 


\section{References}

1. Eisenberg ME, Neumark-Sztainer D, Paxton SJ. Five-year change in body satisfaction among adolescents. J Psychosom Res. 2006;61(4):521-527.

2. Haug E, Rasmussen M, Samdal O, et al. Overweight in school-aged children and its relationship with demographic and lifestyle factors: results from the WHO-Collaborative Health Behaviour in School-aged Children (HBSC) study. Int J Public Health. 2009;54 Suppl 2:167-179.

3. Reilly JJ. Descriptive epidemiology and health consequences of childhood obesity. Best Pract Res Clin Endocrinol Metab. 2005;19(3):327-341.

4. Due P, Krolner R, Rasmussen M, et al. Pathways and mechanisms in adolescence contribute to adult health inequalities. Scand J Public Health. 2011;39(6 Suppl):62-78.

5. Park E. Overestimation and underestimation: adolescents' weight perception in comparison to BMI-based weight status and how it varies across socio-demographic factors. J Sch Health. 2011;81(2):57-64.

6. Chung A, Backholer K, Wong E, et al. Trends in child and adolescent obesity prevalence according to socioeconomic position: protocol for a systematic review. Syst Rev. 2014;3(1):524053-3-52.

7. Marild S, Bondestam M, Bergstrom R, et al. Prevalence trends of obesity and overweight among 10-year-old children in western Sweden and relationship with parental body mass index. Acta Paediatr. 2004;93(12):1588-1595.

8. Sweeting H, West P, Young R. Obesity among Scottish 15 year olds 1987-2006: prevalence and associations with socio-economic status, well-being and worries about weight. BMC Public Health. 2008;8:404-2458-8-404.

9. Veldhuis L, Vogel I, van Rossem L, et al. Influence of maternal and child lifestyle-related characteristics on the socioeconomic inequality in overweight and obesity among 5-year-old children; the "Be Active, Eat Right" Study. Int J Environ Res Public Health. 2013;10(6):23362347.

10. Sweeting HN. Gendered dimensions of obesity in childhood and adolescence. Nutr J. 2008;7:1-2891-7-1.

11. Boylan SM, Gill TP, Hare-Bruun H, et al. Associations between adolescent and adult socioeconomic status and risk of obesity and overweight in Danish adults. Obes Res Clin Pract. 2014;8(2):e163-71.

12. Parsons TJ, Power C, Logan S, et al. Childhood predictors of adult obesity: a systematic review. Int J Obes Relat Metab Disord. 1999;23 Suppl 8:S1-107. 
13. Singh AS, Mulder C, Twisk JW, et al. Tracking of childhood overweight into adulthood: a systematic review of the literature. Obes Rev. 2008;9(5):474-488.

14. Zeller MH, Reiter-Purtill J, Ramey C. Negative peer perceptions of obese children in the classroom environment. Obesity (Silver Spring). 2008;16(4):755-762.

15. Must A, Strauss RS. Risks and consequences of childhood and adolescent obesity. Int J Obes Relat Metab Disord. 1999;23 Suppl 2:S2-11.

16. Muris $\mathrm{P}$, Meesters C, van de Blom W, et al. Biological, psychological, and sociocultural correlates of body change strategies and eating problems in adolescent boys and girls. Eat Behav. 2005;6(1):11-22.

17. Cole TJ, Bellizzi MC, Flegal KM, et al. Establishing a standard definition for child overweight and obesity worldwide: international survey. BMJ. 2000;320(7244):1240-1243.

18. Maynard LM, Wisemandle W, Roche AF, et al. Childhood body composition in relation to body mass index. Pediatrics. 2001;107(2):344-350.

19. Bini V, Celi F, Berioli MG, et al. Body mass index in children and adolescents according to age and pubertal stage. Eur J Clin Nutr. 2000;54(3):214-218.

20. Eissa MA, Dai S, Mihalopoulos NL, et al. Trajectories of fat mass index, fat free-mass index, and waist circumference in children: Project HeartBeat! Am J Prev Med. 2009;37(1 Suppl):S349 .

21. Freedman DS, Serdula MK, Srinivasan SR, et al. Relation of circumferences and skinfold thicknesses to lipid and insulin concentrations in children and adolescents: the Bogalusa Heart Study. Am J Clin Nutr. 1999;69(2):308-317.

22. Pouliot MC, Despres JP, Lemieux S, et al. Waist circumference and abdominal sagittal diameter: best simple anthropometric indexes of abdominal visceral adipose tissue accumulation and related cardiovascular risk in men and women. Am J Cardiol. 1994;73(7):460-468.

23. Flodmark CE, Sveger T, Nilsson-Ehle P. Waist measurement correlates to a potentially atherogenic lipoprotein profile in obese 12-14-year-old children. Acta Paediatr. 1994;83(9):941945 .

24. Savva SC, Tornaritis M, Savva ME, et al. Waist circumference and waist-to-height ratio are better predictors of cardiovascular disease risk factors in children than body mass index. Int $\mathbf{J}$ Obes Relat Metab Disord. 2000;24(11):1453-1458.

25. Rankinen T, Kim SY, Perusse L, et al. The prediction of abdominal visceral fat level from body composition and anthropometry: ROC analysis. Int J Obes Relat Metab Disord. 1999;23(8):801-809. 
26. Daniels SR, Khoury PR, Morrison JA. Utility of different measures of body fat distribution in children and adolescents. Am J Epidemiol. 2000;152(12):1179-1184.

27. McCarthy HD. Body fat measurements in children as predictors for the metabolic syndrome: focus on waist circumference. Proc Nutr Soc. 2006;65(4):385-392.

28. Han TS, van Leer EM, Seidell JC, et al. Waist circumference as a screening tool for cardiovascular risk factors: evaluation of receiver operating characteristics (ROC). Obes Res. 1996;4(6):533-547.

29. McCarthy HD, Cole TJ, Fry T, et al. Body fat reference curves for children. Int J Obes (Lond). 2006;30(4):598-602.

30. Wells JC. Sexual dimorphism of body composition. Best Pract Res Clin Endocrinol Metab. 2007;21(3):415-430.

31. Taylor RW, Grant AM, Williams SM, et al. Sex differences in regional body fat distribution from pre- to postpuberty. Obesity (Silver Spring). 2010;18(7):1410-1416.

32. Pinyerd B, Zipf WB. Puberty-timing is everything! J Pediatr Nurs. 2005;20(2):75-82.

33. Bourguignon JP, Juul A. Normal female puberty in a developmental perspective. Endocr Dev. 2012;22:11-23.

34. Apter D, Hermanson E. Update on female pubertal development. Curr Opin Obstet Gynecol. 2002;14(5):475-481.

35. Aksglaede L, Juul A, Olsen LW, et al. Age at puberty and the emerging obesity epidemic. PLoS One. 2009;4(12):e8450.

36. Biro FM, Lucky AW, Simbartl LA, et al. Pubertal maturation in girls and the relationship to anthropometric changes: pathways through puberty. J Pediatr. 2003;142(6):643-646.

37. Hillman JB, Biro FM. Dynamic changes of adiposity during puberty: life may not be linear. J Adolesc Health. 2010;47(4):322-323.

38. Davison KK, Susman EJ, Birch LL. Percent body fat at age 5 predicts earlier pubertal development among girls at age 9. Pediatrics. 2003;111(4 Pt 1):815-821.

39. Biro FM, Khoury P, Morrison JA. Influence of obesity on timing of puberty. Int J Androl. 2006;29(1):272-7; discussion 286-90.

40. Bratberg GH, Nilsen TI, Holmen TL, et al. Early sexual maturation, central adiposity and subsequent overweight in late adolescence. a four-year follow-up of 1605 adolescent Norwegian boys and girls: the Young HUNT study. BMC Public Health. 2007;7:54. 
41. Buyken AE, Karaolis-Danckert N, Remer T. Association of prepubertal body composition in healthy girls and boys with the timing of early and late pubertal markers. Am J Clin Nutr.

2009;89(1):221-230.

42. Kindblom JM, Lorentzon M, Norjavaara E, et al. Pubertal timing is an independent predictor of central adiposity in young adult males: the Gothenburg osteoporosis and obesity determinants study. Diabetes. 2006;55(11):3047-3052.

43. Kaplowitz PB, Slora EJ, Wasserman RC, et al. Earlier onset of puberty in girls: relation to increased body mass index and race. Pediatrics. 2001;108(2):347-353.

44. Crocker MK, Stern EA, Sedaka NM, et al. Sexual dimorphisms in the associations of BMI and body fat with indices of pubertal development in girls and boys. J Clin Endocrinol Metab. 2014;99(8):E1519-29.

45. Biro FM. Puberty. Adolesc Med State Art Rev. 2007;18(3):425-33, v.

46. Silbereisen R, Kracke B. Self-reported maturational timing and adaptation in adolescence. I: Schulenberg J, Maggs J, Hurrelmann K, red. Health risks and developmental transitions in adolescence. Cambridge, Cambridge University Press; 1997.

47. Andrist LC. Media images, body dissatisfaction, and disordered eating in adolescent women. MCN Am J Matern Child Nurs. 2003;28(2):119-123.

48. Siegel JM, Yancey AK, Aneshensel CS, et al. Body image, perceived pubertal timing, and adolescent mental health. J Adolesc Health. 1999;25(2):155-165.

49. Williams JM, Currie C. Self-esteem and physical development in early adolescence: pubertal timing and body image. Journal of Early Adolescence. 2000;20:129-149.

50. Richards MH, Casper RC, Larson R. Weight and eating concerns among pre- and young adolescent boys and girls. J Adolesc Health Care. 1990;11(3):203-209.

51. Latner JD, Stunkard AJ. Getting worse: the stigmatization of obese children. Obes Res. 2003;11(3):452-456.

52. Wilson RE, Latner JD, Hayashi K. More than just body weight: the role of body image in psychological and physical functioning. Body Image. 2013;10(4):644-647.

53. Neumark-Sztainer D, Levine MP, Paxton SJ, et al. Prevention of body dissatisfaction and disordered eating: What next? Eat Disord. 2006;14(4):265-285.

54. Smolak L, Stein JA. The relationship of drive for muscularity to sociocultural factors, selfesteem, physical attributes gender role, and social comparison in middle school boys. Body Image. 2006;3(2):121-129. 
55. Burrowes N. Body Image - a rapid evidence assessment of the literature. A project on behalf of the Government Equalities Office. 2013.

56. Page A, Fox KR. Is body composition important in young people's weight management decision-making? Int J Obes Relat Metab Disord. 1998;22(8):786-792.

57. Hargreaves DA, Tiggemann M. 'Body image is for girls': a qualitative study of boys' body image. J Health Psychol. 2006;11(4):567-576.

58. Kilpatrick M, Ohannessian C, Bartholomew JB. Adolescent weight management and perceptions: an analysis of the National Longitudinal Study of Adolescent Health. J Sch Health. 1999;69(4):148-152.

59. Ojala K, Vereecken C, Valimaa R, et al. Attempts to lose weight among overweight and nonoverweight adolescents: a cross-national survey. Int J Behav Nutr Phys Act. 2007;4:50.

60. Ahren-Moonga J, Silverwood R, Klinteberg BA, et al. Association of higher parental and grandparental education and higher school grades with risk of hospitalization for eating disorders in females: the Uppsala birth cohort multigenerational study. Am J Epidemiol. 2009;170(5):566575 .

61. McCourt HJ, Draffin CR, Woodside JV, et al. Dietary patterns and cardiovascular risk factors in adolescents and young adults: the Northern Ireland Young Hearts Project. Br J Nutr.

2014;112(10):1685-1698.

62. DiClemente RJ, Wingood GM, Crosby R, et al. Parental monitoring: association with adolescents' risk behaviors. Pediatrics. 2001;107(6):1363-1368.

63. Santrock J. Adolescence. 11 uppl. New York: McGraw-Hill; 2007.

64. Goodell LS, Pierce MB, Amico KR, et al. Parental information, motivation, and behavioral skills correlate with child sweetened beverage consumption. J Nutr Educ Behav. 2012;44(3):240245 .

65. O'Dea JA, Wilson R. Socio-cognitive and nutritional factors associated with body mass index in children and adolescents: possibilities for childhood obesity prevention. Health Educ Res. 2006;21(6):796-805.

66. Richter M, Vereecken CA, Boyce W, et al. Parental occupation, family affluence and adolescent health behaviour in 28 countries. Int J Public Health. 2009;54(4):203-212.

67. Lien N, Kumar BN, Holmboe-Ottesen G, et al. Assessing social differences in overweight among 15- to 16-year-old ethnic Norwegians from Oslo by register data and adolescent selfreported measures of socio-economic status. Int J Obes (Lond). 2007;31(1):30-38. 
68. Vereecken C, Dupuy M, Rasmussen M, et al. Breakfast consumption and its sociodemographic and lifestyle correlates in schoolchildren in 41 countries participating in the HBSC study. Int J Public Health. 2009;54 Suppl 2:180-190.

69. Vartanian LR, Schwartz MB, Brownell KD. Effects of soft drink consumption on nutrition and health: a systematic review and meta-analysis. Am J Public Health. 2007;97(4):667-675.

70. Timlin MT, Pereira MA, Story M, et al. Breakfast eating and weight change in a 5-year prospective analysis of adolescents: Project EAT (Eating Among Teens). Pediatrics. 2008;121(3):e638-45.

71. Cooke LJ, Wardle J. Age and gender differences in children's food preferences. Br J Nutr. 2005;93(5):741-746.

72. Westerberg-Jacobson J, Edlund B, Ghaderi A. A 5-year longitudinal study of the relationship between the wish to be thinner, lifestyle behaviours and disturbed eating in 9-20-year old girls. Eur Eat Disord Rev. 2010;18(3):207-219.

73. Strauss RS, Pollack HA. Social marginalization of overweight children. Arch Pediatr Adolesc Med. 2003;157(8):746-752.

74. Mikkila V, Lahti-Koski M, Pietinen P, et al. Associates of obesity and weight dissatisfaction among Finnish adolescents. Public Health Nutr. 2003;6(1):49-56.

75. Strauss RS. Self-reported weight status and dieting in a cross-sectional sample of young adolescents: National Health and Nutrition Examination Survey III. Arch Pediatr Adolesc Med. 1999;153(7):741-747.

76. Zullig K, Ubbes VA, Pyle J, et al. Self-reported weight perceptions, dieting behavior, and breakfast eating among high school adolescents. J Sch Health. 2006;76(3):87-92.

77. Strauss RS, Mir HM. Smoking and weight loss attempts in overweight and normal-weight adolescents. Int J Obes Relat Metab Disord. 2001;25(9):1381-1385.

78. Neumark-Sztainer D, Wall M, Guo J, et al. Obesity, disordered eating, and eating disorders in a longitudinal study of adolescents: how do dieters fare 5 years later? J Am Diet Assoc. 2006;106(4):559-568.

79. Sjoberg A, Barrenas ML, Brann E, et al. Body size and lifestyle in an urban population entering adulthood: the 'Grow up Gothenburg' study. Acta Paediatr. 2012;101(9):964-972.

80. Pedersen TP, Holstein BE, Flachs EM, et al. Meal frequencies in early adolescence predict meal frequencies in late adolescence and early adulthood. BMC Public Health. 2013;13:4452458-13-445. 
81. Currie C, Roberts C, Morgan A, et al., red. Young people's health in context. Health Behaviour in School-aged Children (HBSC) study: international report from the 2001/2002 survey. Health Policy for Children and Adolescents, No. 4. Denmark: World Health Organization; 2004.

82. Currie $\mathrm{C}$ et al., eds., red. Social determinants of health and well-being among young people. Health Behaviour in School-aged Children (HBSC) study: international report from the 2009/2010 survey. (Health Policy for Children and Adolescents, No. 6). Copenhagen: WHO Regional Office for Europe; 2012.

83. McCarthy HD, Jarrett KV, Crawley HF. The development of waist circumference percentiles in British children aged 5.0-16.9 y. Eur J Clin Nutr. 2001;55(10):902-907.

84. Carskadon MA, Acebo C. A self-administered rating scale for pubertal development. J Adolesc Health. 1993;14(3):190-195.

85. Currie C, Nic Gabhainn S, Godeau E, et al. The Health Behaviour in School-aged Children: WHO Collaborative Cross-National (HBSC) study: origins, concept, history and development 1982-2008. Int J Public Health. 2009;54 Suppl 2:131-139.

86. Statistics Sweden. MIS 1982:4 SEI, Socioekonomisk indelning (SEI); 1984: http://www.scb.se/sv_/Dokumentation/Klassifikationer-och-standarder/Socioekonomiskindelning-SEI/.

87. Fredrickson J, Kremer P, Swinburn B, et al. Biopsychosocial correlates of weight status perception in Australian adolescents. Body Image. 2013;10(4):552-557.

88. Paxton SJ, Neumark-Sztainer D, Hannan PJ, et al. Body dissatisfaction prospectively predicts depressive mood and low self-esteem in adolescent girls and boys. J Clin Child Adolesc Psychol. 2006;35(4):539-549.

89. Rand CS, Resnick JL. The "good enough" body size as judged by people of varying age and weight. Obes Res. 2000;8(4):309-316.

90. Xanthopoulos MS, Borradaile KE, Hayes S, et al. The impact of weight, sex, and race/ethnicity on body dissatisfaction among urban children. Body Image. 2011;8(4):385-389.

91. Paxton SJ, Eisenberg ME, Neumark-Sztainer D. Prospective predictors of body dissatisfaction in adolescent girls and boys: a five-year longitudinal study. Dev Psychol. 2006;42(5):888-899.

92. Neovius MG, Linne YM, Barkeling BS, et al. Sensitivity and specificity of classification systems for fatness in adolescents. Am J Clin Nutr. 2004;80(3):597-603.

93. Maynard LM, Galuska DA, Blanck HM, et al. Maternal perceptions of weight status of children. Pediatrics. 2003;111(5 Pt 2):1226-1231. 
94. Goodman E, Hinden BR, Khandelwal S. Accuracy of teen and parental reports of obesity and body mass index. Pediatrics. 2000;106(1 Pt 1):52-58.

95. Demerath EW, Schubert CM, Maynard LM, et al. Do changes in body mass index percentile reflect changes in body composition in children? Data from the Fels Longitudinal Study.

Pediatrics. 2006;117(3):e487-95.

96. Bergstrom E, Stenlund H, Svedjehall B. Assessment of body perception among Swedish adolescents and young adults. J Adolesc Health. 2000;26(1):70-75.

97. Thoma ME, Hediger ML, Sundaram R, et al. Comparing apples and pears: women's perceptions of their body size and shape. J Womens Health (Larchmt). 2012;21(10):1074-1081.

98. Rhodes SK, O'Neil PM. Effects of body fat distribution on body size estimation accuracy among obese women. Int J Obes Relat Metab Disord. 1997;21(3):250-253.

99. Knowles AM, Niven AG, Fawkner SG, et al. A longitudinal examination of the influence of maturation on physical self-perceptions and the relationship with physical activity in early adolescent girls. J Adolesc. 2009;32(3):555-566.

100. Brooks-Gunn J, Warren MP. The psychological significance of secondary sexual characteristics in nine- to eleven-year-old girls. Child Dev. 1988;59(4):1061-1069.

101. Ohring R, Graber JA, Brooks-Gunn J. Girls' recurrent and concurrent body dissatisfaction: correlates and consequences over 8 years. Int J Eat Disord. 2002;31(4):404-415.

102. Cohane GH, Pope HG,Jr. Body image in boys: a review of the literature. Int J Eat Disord. 2001;29(4):373-379.

103. Bratberg GH, Nilsen TI, Holmen TL, et al. Combined influence of early sexual maturation and central adiposity on subsequent stature. A four-year follow-up of 1,605 Norwegian boys and girls: the Young-HUNT study. Eur J Pediatr. 2006;165(11):787-793.

104. Biro FM, Wolff MS, Kushi LH. Impact of yesterday's genes and today's diet and chemicals on tomorrow's women. J Pediatr Adolesc Gynecol. 2009;22(1):3-6.

105. Wohlfahrt-Veje C, Andersen HR, Schmidt IM, et al. Early breast development in girls after prenatal exposure to non-persistent pesticides. Int J Androl. 2012;35(3):273-282.

106. Juul A, Teilmann G, Scheike T, et al. Pubertal development in Danish children: comparison of recent European and US data. Int J Androl. 2006;29(1):247-55; discussion 286-90.

107. Aksglaede L, Sorensen K, Petersen JH, et al. Recent decline in age at breast development: the Copenhagen Puberty Study. Pediatrics. 2009;123(5):e932-9. 
108. Neumark-Sztainer D, Paxton SJ, Hannan PJ, et al. Does body satisfaction matter? Five-year longitudinal associations between body satisfaction and health behaviors in adolescent females and males. J Adolesc Health. 2006;39(2):244-251.

109. Bun CJ, Schwiebbe L, Schutz FN, et al. Negative body image and weight loss behaviour in Dutch school children. Eur J Public Health. 2012;22(1):130-133.

110. Cragun D, Ata RN, Debate RD, et al. Gender comparisons of unhealthy weight-control behaviors among sixth-Graders. J Nutr Educ Behav. 2013;45(5):450-454.

111. van den Berg PA, Keery H, Eisenberg M, et al. Maternal and adolescent report of mothers' weight-related concerns and behaviors: longitudinal associations with adolescent body dissatisfaction and weight control practices. J Pediatr Psychol. 2010;35(10):1093-1102.

112. Corning AF, Gondoli DM, Bucchianeri MM, et al. Preventing the development of body issues in adolescent girls through intervention with their mothers. Body Image. 2010;7(4):289295.

113. Manios Y, Moschonis G, Grammatikaki E, et al. Determinants of childhood obesity and association with maternal perceptions of their children's weight status: the "GENESIS" study. $\mathrm{J}$ Am Diet Assoc. 2010;110(10):1527-1531.

114. Dammann KW, Smith C, Richards R. Low-income minority and homeless mothers' perceptions of their 9-13 year-old children's weight status, diet, and health. Matern Child Health J. 2011;15(1):106-114.

115. Goodell LS, Pierce MB, Bravo CM, et al. Parental perceptions of overweight during early childhood. Qual Health Res. 2008;18(11):1548-1555.

116. Block JP, DeSalvo KB, Fisher WP. Are physicians equipped to address the obesity epidemic? Knowledge and attitudes of internal medicine residents. Prev Med. 2003;36(6):669675.

117. Berge JM, Wall M, Loth K, et al. Parenting style as a predictor of adolescent weight and weight-related behaviors. J Adolesc Health. 2010;46(4):331-338.

118. Thibault H, Contrand B, Saubusse E, et al. Risk factors for overweight and obesity in French adolescents: physical activity, sedentary behavior and parental characteristics. Nutrition. 2010;26(2):192-200.

119. Hallstrom L, Vereecken CA, Ruiz JR, et al. Breakfast habits and factors influencing food choices at breakfast in relation to socio-demographic and family factors among European adolescents. The HELENA Study. Appetite. 2011;56(3):649-657.

120. Strauss RS. Comparison of measured and self-reported weight and height in a crosssectional sample of young adolescents. Int J Obes Relat Metab Disord. 1999;23(8):904-908. 
121. Sjoberg A, Lissner L, Albertsson-Wikland K, et al. Recent anthropometric trends among Swedish school children: evidence for decreasing prevalence of overweight in girls. Acta Paediatr. 2008;97(1):118-123.

122. Currie C, eds. International reports. Copenhagen: WHO Regional Office for Europe; 2013: http://www.hbsc.org/publications/international/.

123. Whitehead M, Dahlgren G. What can be done about inequalities in health? Lancet. 1991;338(8774):1059-1063.

124. Kristenson M, Cedersund E, Dahlstedt M, et al. Östgötakommissionen för Folkhälsa slutrapport (in Swedish). Linkoping: Region Ostergotland; 2014. 



\section{Papers}

The articles associated with this thesis have been removed for copyright reasons. For more details about these see:

http://urn.kb.se/resolve?urn=urn:nbn:se:liu:diva-123861 